\title{
WHAT YOU DON'T SEE CAN HURT YOU: AWARENESS CUES TO PROFILE INDIRECT COMPETITORS
}

\author{
STEPHEN T. DOWNING \\ JIN-SU KANG \\ National Chiao Tung University \\ GIDEON D. MARKMAN \\ Colorado State University and Gent University
}

\begin{abstract}
The awareness-motivation-capability (AMC) framework instructs firms to be aware of rivals, yet it offers limited guidance on how to profile those who are not yet rivals but stand to become so. Because rivals are embedded in dyads, triads, tetrads, etc., a multilevel view can unearth awareness cues that specify a hostility profile and make the awareness construct prescient. Studying thousands of competitive encounters over 10 years, we show that, at the firm and dyad levels, diversification and asymmetric pressure (differential exposure to competitive pressure) are reliable cues predicting competitive encounters. At the network level, convergence drives triadic encounters (competition with a rival's rival), and the degree of separation among indirect competitors defines the outer bounds of the hostility profile. Specifically, direct rivals and second- and third-degree indirect competitors merit awareness-more distal players do not. Together, the awareness cues and hostility profile delineate the conceptual bound within which awareness is prescient and beyond which it is misplaced. Challenging several assumptions, our study shows that an arena view assists in predicting cross-industry competition; applying firm, dyad, and network levels of analysis is advisable to better foresee competition; and indirect competitors are "profilable," allowing us to "see" rivals even before they strike.
\end{abstract}

Competitive dynamics (CD) research explains when, where, why, how, and under what conditions firms compete. It is therefore a body of literature that measures, describes, and predicts interfirm competitive engagements. To better understand and foresee competitive encounters, the domain has long been complemented by the awareness-motivation-capability (AMC) framework, which explains that competition

The authors would like to thank $A M J$ 's deputy editor, Marc Gruber, and three anonymous reviewers for providing insightful feedback and asking thoughtful questions-your engagement assisted tremendously with the advancement of this manuscript. We are grateful for the developmental comments and research suggestions from Javier Gimeno, Eric Quintane, Laura Albareda, and Frank Rothaermel. We also appreciate the feedback from seminar participants at Australian National University, Colorado State University, New York University Tandon School of Engineering, University of Texas-Arlington, Gent University, and Waikato University, as well as session participants at the annual meetings of the Academy of Management (2017, Atlanta) and Strategic Management Society (2017, Houston). Finally, we thank the Ministry of Science and Technology in Taiwan for financial support (MOST-107-2410-H-009-052 and MOST105-2420-H-009-012-DR). ensues when firms are aware of a threat or opportunity and possess both motivation and capability to attack rivals or defend themselves (Chen, 1996; Chen \& Miller, 2012; Smith, Ferrier, \& Ndofor, 2001; Yu \& Cannella, 2007). Focusing on the awareness construct (the first in the AMC framework), it is clear that scholars and firms are acutely aware of direct rivals (Chen \& Miller, 2012), but they are often ill-informed about spotting, appraising, and prioritizing indirect competitors-those who are not yet rivals today but could become so in the future. ${ }^{1}$ Given that rivals are embedded in dyads, triads, tetrads, and so on, we edify the AMC framework by developing a hostility profile-an industry-agnostic competitor identification prism based on four interdependent awareness cues at the firm, dyad, and network levels. This profile makes the awareness construct better calibrated and more prescient to spot indirect competitors.

Using 10 years of data (2007-2016) from 15,824, 693 dyad-year observations on 142,446 competitive

\footnotetext{
${ }^{1}$ Indirect competitors may include "substitutors, potential competitors, latent substitutors, vertically differentiated rivals" (Peteraf \& Bergen, 2003: 1031), complementors, new entrants, and other in-the-making rivals.
} 
encounters among firms in the customer experience management (CEM) arena, our study makes several contributions to the Special Research Forum (SRF) "New Ways of Seeing"; two contributions in particular deserve elaboration, so we describe these chronologically to align with the structure of the paper. First, currently, the AMC framework assists CD research by profiling rivals based on their industry membership, and, because firms are often more connected to each other within than across industries (Chen, 1996), this approach has served the field well. Reality, however, shows that competitors cross industry precincts (McGrath, 2013), which is one reason why an industry-based awareness construct is not as predictive as it could be. For example, a century ago, railroad barons focused their awareness on direct rivals-other railway firms-and were blindsided by indirect competitors, namely automakers (Desarbo, Grewal, \& Wind, 2006; Levitt, 1960). More recently, the rivalry among Nanogen, Motorola, Massachusetts Institute of Technology, and Genometrix (a biotech startup, multinational telecom, university, and manufacturer, respectively) illustrates that to be prescient, competitor identification modalities should (i) use industry-independent awareness cues, and (ii) recognize that competition is often multisided. By taking an arena view, framing competition as relational, and triangulating awareness in terms of anteceding cues, we afford scholars a new way of sighting indirect competitors before they become direct rivals.

Second, firms face some direct rivals and a much greater number of indirect competitors. While firms are aware of their direct rivals, discerning the bona fide high-risk from no-risk indirect competitors is a daunting task, with which the AMC framework currently offers limited help. Certainly, not every indirect competitor will become a direct rival, and monitoring or even affording attention to every firm is impractical (March \& Simon, 1958; Ocasio, 1997). Therefore, there is a clear need to profile indirect competitors and bound the awareness construct by demarcating its outer reach (Bansal, Kim, \& Wood, 2018). We show that when the cues are applied together, the hostility profile guides firms to extend their awareness up to and including-but not beyond-the rivals of their rivals' rivals (third-degree indirect competitors). In fact, a key contribution of the hostility profile is to define the conditions under which indirect competitors can become direct rivals, and beyond which such threat becomes insignificant.

To recap, past research has used awareness primarily to study known, direct rivals in a single industry, and rarely to preemptively spot indirect or cross-industry competitors before hostility ensues. Using four triangulating awareness cues, we develop a prescient hostility profile that assists in detecting which indirect competitors stand to become direct rivals. By making the awareness construct predictive, we show that an arena view is highly prognostic of cross-industry competition; that firm, dyad, and network levels of analysis assist in "seeing" competitors before they strike; and that indirect competitors are "profilable." Our methodology narrows the theory-practice gap (Kryscynski \& Ulrich, 2015)—segmenting indirect competitors before they become direct rivals is vital for reducing a firm's vulnerability.

\section{BACKGROUND}

Competitive encounters do not emerge randomly, which is why competitor identification and its fundamental question-i.e., who are a focal firm's rivals? are central to CD research (Gur \& Greckhamer, 2019; Withers, Ireland, Miller, Harrison, \& Boss, 2018). The AMC framework is instrumental in this area because it explains that a firm can react to rivals or initiate a competitive move when it is aware of a threat or opportunity to strike and has the motivation and capability to act or respond (Chen, 1996; Smith et al., 2001; Yu \& Cannella, 2007). Chen and Miller (2012) detailed the relevance of the AMC framework in diverse contexts-e.g., competitive interactions, strategic repertoires, multimarket competition, competitor analysis, and competitive perceptions. The awareness construct is a conceptual instrument for understanding how firms detect rivals in diverse contexts, such as market entry (Baum \& Korn, 1996; Haveman \& Nonnemaker, 2000; Markman \& Waldron, 2014), mergers and acquisitions (M\&As) (Haleblian, McNamara, Dykes, \& Kolev, 2012), exits (Girma, Greenaway, \& Kneller, 2003), and even firm closures (Headd, 2003).

Despite ample research on the motivation and capability constructs (Bennett \& Pierce, 2016; Hsieh, Tsai, \& Chen, 2015; Pacheco \& Dean, 2015; Sirmon, Hitt, Arregle, \& Campbell, 2010), studies on the awareness construct remain limited (Guo, Yu, \& Gimeno, 2017). This is a problem, because awareness not only precedes the motivation and capability to act, but also guides firms' attention and intelligencegathering efforts before rivalry ensues (Chen, Su, \& Tsai, 2007). In the absence of prescient awareness, even a highly motivated and capable firm will miss competitive signals (Withers et al., 2018) or struggle to defend itself (Guo et al., 2017). Insufficient or 
misguided awareness interferes with the discernment of friends from foes (Sytch \& Tatarynowicz, 2014), impedes the prioritization of threat, hampers the matching of competitive threats with adequate motivation and capability to react, and generally escalates the cost of competition. However, when firms are well aware of prebattle threats, they can better channel their motivation and capabilities to preempt, face, or avoid impending hostility (Chen et al., 2007).

Unable to deliver on the predictive intent of the awareness construct, but hoping at least to reduce the misclassification of rivals, AMC studies select samples from narrow sets of rivals within well-defined industry precincts or strategic groups (e.g., Smith, Grimm, Wally, \& Young, 1997). The profiling of rivals based on industry membership aligns with the assumption that firms are aware of competitive threats, but we worry that it keeps the awareness construct underdeveloped and less useful for prebattle identification of new rivals, especially those from other industries or distant indirect competitors. In addition, competitive landscapes are more accurately framed as arenas (McGrath, 2013), as they do not always align with industry boundaries and rivalry is often not confined to standard industry classification (SIC) codes or market boundariese.g., the motivation or capability to compete do not vanish just because rivals represent unrelated industries (Markman, Gianiodis, \& Buchholtz, 2009). Consider a few examples of cross-industry, multisided rivalry: When Amazon started selling cloud computing services, it suddenly began to compete with Microsoft, Google, Salesforce, and IBM, and now competes with USPS, FedEx, and UPS in relation to its delivery service. Similarly, Uber, Lyft, and taxi firms are "typical" rivals, but when Uber started to deliver packages it became a rival to FedEx, UPS, and USPS. We infuse theory with reallife examples because as long as competitor identification research and the awareness construct remain focused on single-sided competition and locked by an industry point of view, such "anomalies" will continue to blindside scholars and firms.

Seeing beyond direct rivals and the development of awareness cues to profile indirect competitors necessitates new perspectives, specialized methods, and a consideration of the interdependence between direct rivals and indirect competitors, including the rivals of a focal firm's rivals, and so on. Though competition is relational, most studies have overlooked how competitive ties span different levels of analysis (Chen \& Miller, 2015; Gimeno, 2004; Li, Eden, Hitt, \& Ireland, 2008; Madhavan, Gnyawali, \& He, 2004; Skilton \& Bernardes, 2015; Tsai, Su, \& Chen, 2011). That is, rivals form dyads that are in turn embedded in higher network levels (triads, tetrads, etc.), so our tenet is that by blending firm-, dyad-, and network-level views to capture firm movement (e.g., altered ties that shift the structure of networks), we can develop a hostility profile to predict which indirect competitors today might become direct rivals tomorrow. Our arena view affords a more prescient awareness construct for profiling indirect competitors, plus we introduce a novel methodology to address the shortcomings of nonrelational studies to multilevel analysis.

We explain the contributions and define key constructs below, but for added clarity, and as a prelude to the theory section, Figure 1 depicts the conceptual model. Four cues triangulate the hostility profile: diversification, asymmetric pressure, convergence, and degree of separation. At the firm level, diversified firms are likely to face competitive encounters, and at the dyadic level, asymmetric pressure (i.e., the differential exposure to competitive pressure) is a significant predictor of competitive encounters. At the network level, convergence-i.e., the encroachment of markets upon each other-is associated with competitive encounters. The first three awareness cues (i.e., diversification, asymmetric pressure, and convergence) define the inclusion criteria for possible hostility. A final awareness cue, the degree of separation between firms, is the exclusion criterion, showing that indirect competitors who are four or more degrees of separation away from a focal firm are unlikely to become direct rivals. Collectively, these cues define the hostility profile, which is the higher conceptual raison d'être construct in our study.

\section{THEORY DEVELOPMENT AND HYPOTHESES}

As noted, rivals form dyads, triads, etc. Mirroring this logic, our hypotheses start at the firm level, followed by the dyadic and finally network levels. We also begin with a firm-level awareness cue because firms are the most basic actors in competitive encounters.

\section{Diversification: A Firm-Level Awareness Cue}

Several firm-level attributes might predict competitive encounters; however, given the early conceptual stage regarding the development of 
FIGURE 1

Conceptual Model

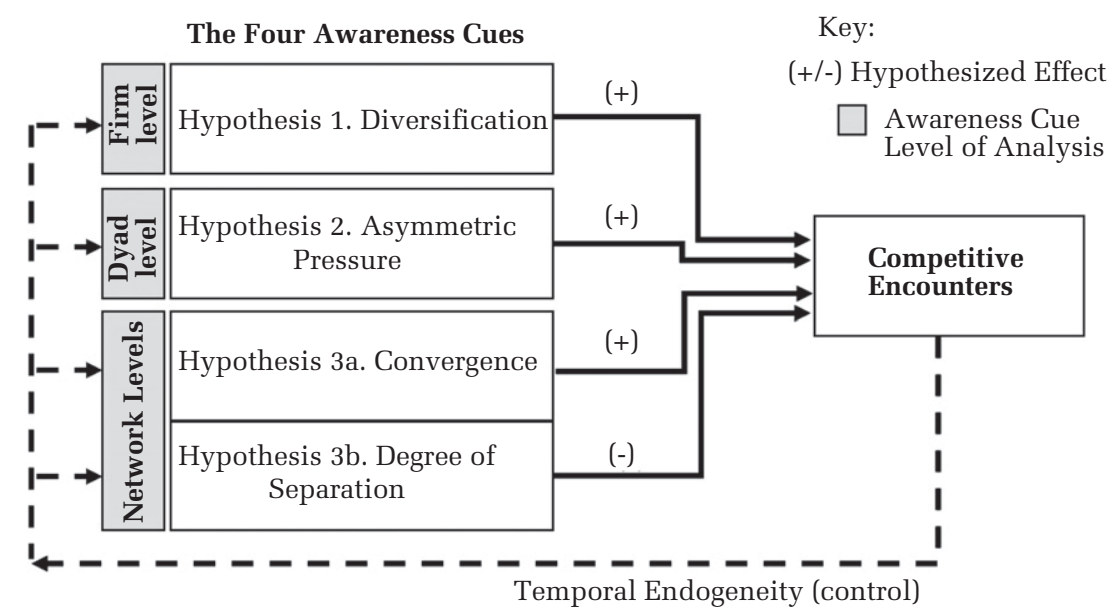

awareness cues and the need for a reliable, industryunallied cue that correlates with firm movement, we focus on diversification - the extent to which a firm expands the scope of its operation, products, or services beyond its core business, market, or industry. Serving also as a shock absorber, diversification assists firms with adaptation to changing market conditions (Davis, Diekmann, \& Tinsley, 1994). This can reduce the power of buyers, suppliers, product substitutes, and rivals, and it also attenuates the adverse impact of seasonal fluctuations while enhancing the fit of resources and capabilities with growth-enhancing opportunities. Diversification research has focused on neither awareness cues nor profiling indirect competitors, but it has offered some insights into the diversification-rivalry link. For example, Haleblian et al. (2012) showed that diversification shields a firm from competition, Gimeno (2004) and Haveman and Nonnemaker (2000) reported that diversified firms are less aggressive and less vulnerable to cross-market retaliation, and Miller and Chen (1994) found that diversified firms arouse competitive actions. Despite this limited and not yet converging research, we evince that because diversification is a strong predictor of cross-industry movement (Delios \& Beamish, 1999; Rumelt, 1974; Santalo \& Becerra, 2008)—and is a stable and observable attribute-it can serve as a reliable awareness cue for competitive encounters (Wiersema \& Bowen, 2008).

Highly diversified firms tend to be expansionary even if growth opportunities are outside their markets (Delios \& Beamish, 1999; McGrath, 2013; Penrose, 1959; Rumelt, 1974), which means wide movements both upstream (into manufacturing and supply-chain providers in factor markets) and downstream (toward buyers and end users in product markets) (Priem, Li, \& Carr, 2012). In addition, firm movement increases cross-industry encounters with new rivals (Withers et al., 2018). Relatedly, diversified firms achieve synergies from cross-market and cross-industry acquisitions, and again such movements often bring encounters with unfamiliar rivals (Markman et al., 2009; Ye, Priem, \& Alshwer, 2012). Unlike their undiversified counterparts, diversified firms allocate more resources to subsidize their forays into adjacent, even dissimilar markets, suggesting that they stand to face new rivals. Expansive market entry and crosssectoral movement put diversified firms on a more adversarial path with rivals, some of which may have no choice but to fight back if they have no replacement market into which to retreat (Shen \& Villas-Boas, 2010; Upson, Ketchen, Connelly, \& Ranft, 2012). When highly diversified firms contribute to landscape shifts and market convergence, their movement can be quite destabilizing (Schmidt, Makadok, \& Keil, 2016). Thus, their large budgets and expansion needs explain why diversified firms make wide moves and consequently face players they have not previously encountered.

These distinct properties of diversified firms are not entirely novel, but their role as a precursor to competition is certainly new to CD research and the AMC framework in particular. Thus, we make the following prediction:

Hypothesis 1. The higher the diversification level of a firm, the higher its likelihood of facing competitive encounters. 


\section{Asymmetric Pressure: A Dyad-Level Awareness Cue}

A robust hostility profile requires triangulating cues, so we expand the study to examine which pair of firms might face each other competitively (Baum \& Korn, 1999; Smith et al., 2001). Several dyad-level constructs could play a role, including differences in resource endowment (Chen \& Miller, 2012), market dependence (Pacheco \& Dean, 2015), and spheres of influence (Chen, 1996; Gimeno, 2004), to name a few. Such constructs are useful for profiling existing rivals, but are too myopic to predict the formation of new encounters because they overlook the interrelations among firms and the wider landscape in which firms are embedded (i.e., their positions and pressure they face prior to hostile encounters). Marrying the concepts of competitive asymmetry (Chen \& Miller, 2012) and competitive pressure (D'Aveni, 2002), we redirect attention to asymmetric pressure-i.e., the differential exposure to the cumulative competitive pressure from all competitors. Imagining an aerial view of competitive landscapes might assist in visualizing asymmetric pressure. If Firms A and B are embedded in the same network of direct and indirect competitors, but Firm B's arrangement is more engulfing and more proximal, then Firm B faces stronger competitive pressure (D’Aveni, 2002; Hsieh \& Vermeulen, 2014).

This cue is revelatory for two main reasons. First, as a macro construct, asymmetric pressure accounts for the number of direct and indirect competitors, their arrangement and proximity vis-à-vis a dyad. Unlike direct rivals, indirect competitors are, by definition, farther away from focal firms, but cumulatively they can generate immense competitive pressure as they are more numerous than direct rivals. They are also less predictable-i.e., they come from more distant territories, have unfamiliar profiles, rely on atypical resourcecapability mixes and use different logic-so the competitive pressure they create is neither trivial nor benign (Withers et al., 2018). Second, as noted above, because prior studies have taken a static view that is often market- or industry-based, they have become too myopic to see that dyads are embedded in a wider, multisided, interdependent, and dynamic environment. The asymmetric pressure construct is more encompassing as it considers not only each dyad but also the surrounding, cumulative threats from all competitorsdirect and indirect, regardless of industry membership. Thus, dyadic relations are better understood within the wider competitive pressure that focal firms face.

Several rationales have suggested that a strong asymmetry in competitive pressure precedes the formation of competitive dyads; e.g., the greater the pressure, the more resources firms must revert away from growthenhancing functions and into defensive needs (McGrath, Chen, \& MacMillan, 1998; Withers et al., 2018). In addition, when firms divert resources they erode their momentum, limit their profits, and admit their vulnerability, to the further benefit of rivals (Markman et al., 2009). In fact, competitive pressure is one of the strongest forces to shape competitive behavior, and M\&A research has corroborated that when competitive pressure intensifies, firms become even more vulnerable to attacks (Rogan \& Sorenson, 2014). Just as acute competitive pressure suboptimizes a firm's resource allocation, erodes its momentum, and reveals its vulnerability, minimal competitive pressure affords greater strategic and operational agility. Given a choice, then, firms strike at more vulnerable players rather than those facing equal or less competitive pressure (all else being equal).

To recap, asymmetrical competitive pressure is an intuitive construct for explaining why firms are motivated to compete not with equally exposed targets but with those facing greater competitive pressure; hence, this cue is critical for triangulating the hostility profile. Thus:

Hypothesis 2. Asymmetric pressure between firms in a dyad is positively related to the likelihood of competitive encounters.

\section{Network-Level Awareness Cues}

Firms are not isolated islands. Instead, they are embedded in networks, so the morphology of networks can offer clues about who stands to compete with whom. Network-level cues, in particular, assist by revealing multisided and cross-industry competition. Network studies on collaboration have used the concept of embeddedness to explain several benefits, often with the centrality and openness constructs. However, in competition networks, the goal is to reveal how embeddedness is associated with increased vulnerability, so we explain why convergence and the degree of separation between firms (two network-level awareness cues) also demarcate the hostility profile.

Convergence. The evolution of any competitive landscape-e.g., markets, industries, or arenasentails a dynamic interplay among firms that simultaneously creates and dissolves collaborative and competitive ties between them, thus affecting firms' actions (Gulati \& Gargiulo, 1999). We study all-sided competitive encounters not only because research has often overlooked these engagements, but mainly because-as noted above-dyads are embedded in triads, which are embedded in tetrads, etc., and such 
agglomerated contexts can shed considerable light on which indirect competitors might become direct rivals. We stress network convergence-which occurs when technologies, capabilities, firms, industries, or landscapes coalesce-as it acknowledges firm movement and thus helps to predict which indirect competitors can become direct rivals. For instance, the Internet and fungibility of technology erode industry boundaries, facilitate firm movement, and create interindustry convergence through transitivity (a term used when a rival of a focal firm's rival becomes a direct rival of the focal firm). ${ }^{2}$

The root causes of network convergence and thus transitivity among competitors vary: Diffused synergies, bundled services, integrated products, interoperable technology, and the rise of multisided platforms are all as much related to convergence as are the proliferation of diversified firms and the surge in asymmetric competitive pressure (Schmidt et al., 2016). Research has shown that convergence is associated with not only cross-industry M\&As, Joint Ventures, and alliances, but also with firms' exploitation of customer-specific synergies, and the transfer of competencies across markets (Desarbo et al., 2006; Manral \& Harrigan, 2018; Priem et al., 2012; Uzunca, 2018). In addition, when firms develop a wider user base and apply capabilities across markets, competitive landscapes also converge. As a result, relations, power dynamics, and entire network morphologies change, so convergence is linked to vulnerability as well. For example, manufacturers of digital cameras and GPS units overlooked the convergence of smartphones; IT companies blindsided automakers; and now the financial industry and even nations are scrambling to react to converging (and encroaching) blockchain-based businesses. ${ }^{3}$

Marrying the concept of network convergence with the transitivity principle, our logic is straightforward:

\footnotetext{
${ }^{2}$ Transitivity: The situation that occurs when Firm A competes with Firm B, and Firm B competes with Firm C, and then Firm A competes with Firm C.

${ }^{3}$ Often, geographic proximity can confound or contribute to the concept of network convergence. Our analyses control for this effect, but it is helpful to note that as a network-level awareness cue, convergence neither implies nor requires geographic proximity. The advent of cloud computing-from software-as-a-service pioneers (e.g., Salesforce) to platform- and infrastructure-as-a-service providers (e.g., Amazon Web Services, Google Cloud Platform)-has decoupled service provision from a firm's physical location. Naturally, this is not the case for every competitive arena, yet it clarifies why network convergence is distinct from geographic proximity.
}

Convergence is a prescient awareness cue because when landscapes, technologies, competencies, and customer bases coalesce, they reduce the technological, domain, or geographical "distance" between players and increase the likelihood of transitive encounters where indirect competitors suddenly become direct rivals (Gargiulo, Ertug, \& Galunic, 2009). Thus:

Hypothesis 3a. Convergence is positively related to the likelihood of competitive encounters.

Degree of separation. Unlike distance in geographical space, which is measured in meters or yards, in network space a degree of separation refers to the spatial gaps between firms, such as number and lengths of connections or paths (i.e., those that form dyads, triads, tetrads, pentads, etc.; see our "Methods" section). The separation construct, then, refers neither to geographical distance (only) nor to a single dyadic tie, but instead to the substructures of a competitive landscape. The separation construct is a valuable cue to CD scholars because firms are embedded in ecosystems where their movement impacts the actions taken and tension experienced by all players (Dattée, Alexy, \& Autio, 2018), yet firms cannot and need not be aware of every competitor, so demarcating the bound of the hostility profile is clearly important. Recognizing interdependences, CD scholars have applied network perspectives (Gimeno, 2004; Madhavan et al., 2004), and such effort confirms the coinfluence of local network structure on rivals' perceptions (Tsai et al., 2011) and market entries (Hsieh \& Vermeulen, 2014; Skilton \& Bernardes, 2015). Though clearly helpful, these studies have stopped short of capturing the whole network structure (e.g., "network centralization" in cooperative networks [see Gulati \& Gargiulo, 1999]), which is crucial for bounding the hostility profile. Thus, the degree of separation cue not only captures the substructural tendencies of the competitive landscape to inform awareness, but also sets an upper limit beyond which awareness is no longer needed.

There are several justifications for bounding the hostility profile. Among these is the obvious challenge of scale-based complexity as the number of connections to all other firms increases. ${ }^{4}$ Profiling all indirect competitors in a network and considering their degrees of

\footnotetext{
${ }^{4}$ In a network of all noncommon competitors, the number of indirect competitors at a given degree of separation $(d)$ increases exponentially in proportion to the average number of competitors $(c)$, or $c^{d}$. For example, if each firm in the network had three unique competitors $(c=3)$, then the focal firm would have three rivals at $d=1$; nine indirect competitors at $d=2 ; 27$ at $d=3 ; 81$ at $d=4$, etc.
} 
separation from each other is daunting cognitively and computationally (March \& Olsen, 1976; March \& Simon, 1958; Ocasio, 1997). Another issue is that the transitive-convergence mechanism noted earlier (Hypothesis 3a) will deteriorate, or even break apart, over more rungs of a competition network. Parenthetically, strategic management scholars have used the separation concept to study diverse phenomena. For instance, capabilities and resources can be redeployed across related markets (Penrose, 1959), making M\&As and entry less risky under fewer degrees of separation. Conversely, higher degrees of separation are often associated with incompatibility in capability redeployment, and higher management costs-e.g., unrelated diversification (Ng, 2007) or entry into distant markets (Gruber, MacMillan, \& Thompson, 2013).

Returning to CD research and the degree of separation to bound the hostility profile, we argue that, regardless of landscape substructual complexity and transitivity, scouting or profiling far-removed indirect competitors is unneeded because highly separated players are generally unlikely to close in and become direct rivals. The higher-order conceptual aim, of course, is to define a boundary condition for the hostility profile-to find the "Ultima Thule" network rung(s); the rungs after which awareness will no longer be applicable. Developing this element of our theory is critical because, as noted above, the AMC framework provides neither empirical certitude nor conceptual logic to delineate a cutoff that separates indirect competitors who pose a threat from bona fide nonrivals. Thus, how far-in terms of network rungs-could a focal firm realistically be and yet still clash with its indirect competitors? The absence of theory and lack of empirical evidence on this issue call for a general prediction of a negative association between the degree of separation and competitive encounters, and we await the data analysis to specify the precise degree of separation. In conceptual terms, the separation construct does not define the point at which awareness becomes unreliable; instead, it delineates where awareness is simply no longer needed. Thus:

Hypothesis $3 b$. There is a negative association between the degree of separation among firms in a network and the likelihood of competitive encounters.

\section{METHODS}

\section{Competition Network}

Before delving into the data and variables, it is helpful to elaborate on network terminology and notation. First, rarely do firms either cooperate or compete exclusively; they do both, and collaborative and competitive relations are not simply opposite but quite distinct (Gnyawali \& Madhavan, 2001; Markman et al., 2009; Skilton \& Bernardes, 2015; Sytch \& Tatarynowicz, 2014). The vast majority of network studies have analyzed collaborative ties or, more recently, multiplex ties, but fewer have focused primarily on the structure of competitive relations (a notable exception is Skilton \& Bernardes, 2015). We test for cooperative ties as well, but find that competitive ties are most relevant for awareness because they reveal threats that collaborative ties tend to mask. Second, cooperation and competition networks (Borgatti \& Lopez-Kidwell, 2011; Gimeno, 2004; Li et al., 2008) often require different empirical methodologies. Specifically, Borgatti and LopezKidwell (2011) grouped networks into two main models. Flow models treat ties as conduits for the flow of information and other resources among network members (Granovetter, 1973), whereas architecture models focus on more tangible outcomes (or costs) that accrue to network members based on their position in and adjacency to specific neighbors, their neighbors' neighbors, etc. (Cook \& Emerson, 1978; Cook, Emerson, Gillmore, \& Yamagishi, 1983). Henceforth, we rely on network architecture models, which are better suited to studying adversarial relations as firms maneuver amid competitors, and thus can advance the awareness construct.

Finally, in Figure 2, focal firm A competes with firms B and C in industry I. Firm C also competes with firm $\mathrm{E}$ in industry II, whereas firm $\mathrm{E}$ competes with firms $\mathrm{F}$ and $\mathrm{G}$ in industry III. The degree of

\section{FIGURE 2 Competition Network}

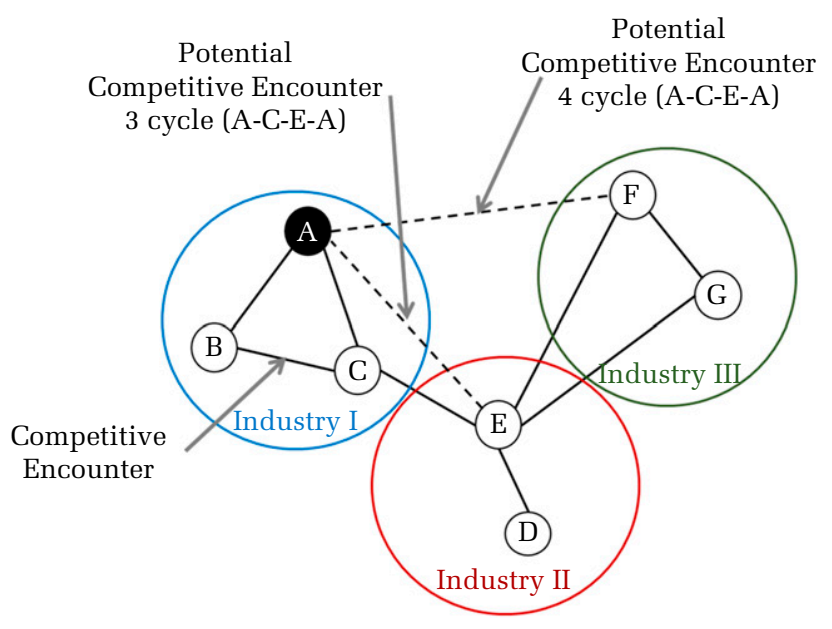


separation between firms $i$ and $j\left(d_{i j}\right)$ is the fewest number of "steps" (i.e., shortest path length) between them. For firms A and B, $d_{A B}=1$; for A and E, $d_{A E}=2$ (second-degree indirect competitors, path: A-C-E); for $\mathrm{A}$ and $\mathrm{F}, d_{A F}=3$ (third-degree indirect competitors, path: A-C-E-F).

With Figure 2 in mind, consider indirect competitors that become direct rivals. If, for example, firm $\mathrm{E}$ engages focal firm $A$, then the competitive encounter between $\mathrm{A}$ and $\mathrm{E}$ causes two major changes. First, a three-cycle rivalry (A-C-E-A) is created among the triad (A, C, E) - an instance of convergence that increases competitive transitivity. Second, the degree of separation between focal firm A and firm $\mathrm{E}$ drops from two to one-their relationship changes from seconddegree (indirect) competitors to first-degree (direct) rivals. Competitive dyads or triads might seem typical, but they are not the only competitive configurations. Less studied, yet more blindsiding, firm F may compete with focal firm $\mathrm{A}$, which would introduce a fourcycle rivalry (A-C-E-F-A), dropping the degree of separation between $\mathrm{A}$ and $\mathrm{F}$ from $d_{A F}=3$ to $d_{A F}=1$. Such a tetradic configuration illustrates an unexpected competitive encounter when the entry of a distant player creates a $k$-cycle rivalry for $k \geq 4$. The movement of indirect competitors and their conversion into direct rivals occurs quite often (e.g., smartphones disrupting the market for GPSs and digital cameras), but with decreasing likelihood as their degree of separation grows, which we address shortly.

\section{Data and Research Setting}

Extant CD research has tended to use data from welldefined, homogenous, relatively stable, and regulated industries; however, to assess the awareness cues under typical conditions we study rivalry in a more representative landscape (Gur \& Greckhamer, 2019) with data spanning 10 years (2007-2016). This context is quite revealing. First, our firms are involved in the CEM arena, which represents a diverse mix of firm sizes, ages, and strategic orientations. These include multiproduct, multinational generalists such as IBM, SAP, Oracle, and Adobe; "unicorns" (i.e., private firms with valuations of $\$ 1$ billion, such as Qualtrics and Medallia); and smaller, single-product startups. Second, unlike many CD studies that have oversampled public companies, our sample is more inclusive and quite representative of the typical private-public ratio: $94 \%$ are private, suggesting that ours is reflective of many business landscapes. This arena is also dynamic, evident in a compound annual growth rate of 19\% (Thompson, 2015). Finally, because CEM firms span several industries, markets and technologies-enterprise social listening, enterprise social networks, enterprise feedback management, digital experience platforms, and customer analytics solutions-they offer a realistic context, including entries and exits, and show network movements including convergence and divergence.

Deviating from past studies that have relied on SIC codes, we obtained our data from CrunchBase, a business graph database that collects, verifies, and validates competitive encounters and venture investment data from technology news articles. ${ }^{5}$ Because firms collaborate and compete, we added data on cooperative relations (alliances and joint ventures) from Thompson Securities Data Company Platinum ${ }^{\mathrm{TM}}$ and compared firm SIC codes from Compustat. Finally, we collected additional data for firm-level controls from Hoover's Mergent Intellect database and PrivCo (Private Company) database, and dyad-level controls came from Thomson Reuters Institutional Holdings database, Compustat, and CrunchBase.

\section{Dependent Variable}

Competitive encounters. The dependent variable (DV) $y_{i j t}$ measures whether a competitive encounter occurred, taking the value of 1 if firms $i$ and $j$ had a competitive encounter in period $t$, and 0 otherwise. As firms rarely compete with all other firms at any given moment, competitor identification studies are more revealing if they follow focal firms over an extended period of time. We analyzed 15,824,693 dyad-year observations with 142,446 competitive encounters related to 25 focal firms and their respective 10,232 direct rivals and indirect competitors (2,920 unique firms) over a 10-year period (2007 to 2016). For context, from 2007 to 2016, Qualtrics (one of our 25 focal firms) faced a total of 7,489 competitive encounters with 531 direct rivals and indirect competitors who represent 29 distinct four-digit SIC codes. For each focal firm, the cohort was chosen to include firms within three degrees of separation from that focal firm in any year, but because firms move, the degrees of separation collectively ranged from one to eight throughout the timeframe. $^{6}$

\footnotetext{
${ }^{5}$ CrunchBase was created by TechCrunch in 2007, and it has operated independently since 2015. https://techcrunch. com/2015/09/22/aolverizon-completes-spinout-of-crunchbasefunded-by-emergence-capital/

${ }^{6}$ The three degrees of separation threshold is far enough to capture unexpected competitive encounters, but still within reasonable cognitive and computational limitations (March, 1991; March \& Simon, 1958).
} 


\section{Independent Variables}

Diversification. We measured diversification (the extent to which a firm expands the scope of its operation, or products or services, beyond its core business, market, or industry) as follows:

$$
\text { Diversification }_{i t}=\sum_{s=1}^{S_{t}} \frac{\sum_{j \in G_{s t}} y_{i j t}}{n_{s t}}, \forall j \neq i
$$

In Equation (1), $G_{s t}$ is the group of firms in the $s^{\text {th }}$ space to which the competitors of firm $i$ belong in time $t$, and $n_{s t}$ is the number of other firms in the $s^{\text {th }}$ space in time $t .^{7}$ This firm-level diversification measure captures dependence upon the competition network structure, creating a foundational awareness cue that reflects the interdependence among arena spaces.

Asymmetric pressure. We operationalize the asymmetric pressure (the differential exposure to cumulative competitive pressure) between firms $i$ and $j$ in period $t$ as follows:

$$
\begin{aligned}
& \text { Asymmetric Pressure }_{i j t} \\
& \quad=\left|C_{i t}(\alpha, \beta)-C_{j t}(\alpha, \beta)\right|, \quad \forall i \neq j
\end{aligned}
$$

In Equation (2), $C_{i t}(\alpha, \beta)=\sum_{j=1}^{n}\left(\alpha+\beta C_{j t}\right) y_{i j t}, \forall j \neq i$ is the competitive pressure (based on Bonacich's [1987] centrality measure) of firm $i$ in period $t$. This has a unique interpretation that we introduce here for adversarial networks with competitive relations-in which dyads compete for resources from a third party (for this measure's origins in adversarial relations of exchange networks, cf. Cook et al. [1983] and Gulati and Sytch [2007]). Specifically, the measure captures the degree to which firm $i$ is exposed to competitive pressure, considering the influence of not only its direct rivals, but their rivals, and so on, cumulatively (Borgatti \& Lopez-Kidwell, 2011). The absolute difference in firm competitive pressures therefore captures dyadic asymmetric pressure in an undirected network. The scaling parameter $\alpha$ can be computed implicitly, but especially important is the decay parameter $\beta$, which must be chosen to control both the type and distance of the pressure effect. Larger absolute values of $\beta$ indicate a distant network effect, while smaller absolute values denote a local effect. The sign of $\beta$ captures the type of network ties, with positive values $(\beta>0)$ representing the informationsharing or resource flows of cooperative networks,

\footnotetext{
${ }^{7}$ The term "space" refers to a competition network community, where competitive relations are defined when firms were seen as rivals by news articles, customers, analysts, and other firm outsiders (Gur \& Greckhamer, 2019).
}

and negative values $(\beta<0)$ representing the competition or bargaining of adversarial networks. Our competition network obviously calls for a negative $\beta$. We expect a distant network effect suited to broadening the scope of awareness, and a range of other negative $\beta$ values are also tested in the "Robustness checks" section.

Convergence. As noted, convergence is the tendency of technologies, capabilities, firms, and industries to coalesce. The network statistic of convergence captures the endogenous dependence of the competition network on the frequency of transitive competitive encounters:

$$
\text { Convergence }_{t}=\sum_{i=1}^{n} \sum_{j=1}^{n} \sum_{k=1}^{n} y_{i j t} y_{j k t} y_{i k t}, \quad \forall i \neq j \neq k
$$

The measure adds 1 whenever all three encounters are present together, forming a three-cycle rivalry.

Degree of separation. Lastly, the degree of separation between firms expands on the convergence measure by counting higher degree $k$-cycles for $k \geq 4$ :

$$
\begin{aligned}
\text { Separation }_{k-1, t}= & \sum_{i=1}^{n} \sum_{j=1}^{n} \ldots \sum_{k=1}^{n} y_{i j t} y_{j l t} \ldots y_{i k t}, \\
& \forall i \neq j \neq l \neq \ldots \neq k
\end{aligned}
$$

Recognizing that a $k$-cycle term may proxy the effect of $k-1$ degrees of separation, we operationalize the substructures of a competitive landscape using counts of network subgraphs (cyclic tetrads, pentads, etc.). By adding $k$-cycle predictors in a range of values for $k$, we can use the pattern of coefficients to represent nontautologically the association between network-level rivalry configurations and the likelihood of individual competitive encounters. ${ }^{8}$ The strength of the relationship depends upon how many configurations the potential competitive encounter would contribute; for example, if four cycles are significantly positive in the network, then competitive encounters that create more endogenous four cycles have a higher likelihood of occurring. Research on the cycle census in exponential random graph models (ERGMs) (Butts, 2006) has shown that decreasing coefficients that eventually become negative for larger significant $k$ values indicate a negative association between degree of separation and competitive encounters (as we hypothesized).

\footnotetext{
${ }^{8}$ Since dyads at one degree of separation are rivals by definition, $y_{i j t}=1 \Leftrightarrow d_{i j t}=1$, the network-level degree of separation proxy may circumvent an otherwise tautological association at the dyad level.
} 


\section{Control Variables}

We used several firm-, dyad-, and network-level controls that could affect competitive encounters. These controls contain exogenous contextual factors and network-related variables.

Firm-level controls. The liability of newness and smallness (Freeman, Carroll, \& Hannan, 1983) is based on the view that a firm's ability to handle more competitive ties is correlated with its age and size. Thus, we include a control for firm age, and, accounting for the impact of size (Chen \& Hambrick, 1995; Miller \& Chen, 1994), we also include the number of employees and sales revenue. Finally, we include competitive pressure as a firm-level control variable.

Dyad-level controls. As dyad-level controls for asymmetric pressure (Hypothesis 2), we used the absolute difference of firm ages, firm ownership status homophily (the tendency of firms with similar traits to encounter each other), and firm branch multimarket contact (MMC). The literature has corroborated the effect of mutual forbearance on rivalry, showing that location can influence whether firms compete or forbear; therefore, we controlled for MMC (Gimeno \& Woo, 1999; Korn \& Baum, 1999). As the firm branch MMC term does not fully capture the necessary exogenous contextual factors for single-branch firms (Lusher, Koskinen, \& Robins, 2013), we complemented this term with a control for headquarters' (HQ) geographic region homophily. We also controlled for the influence of shared investors on competition (Connelly, Lee, Tihanyi, Certo, \& Johnson, 2019) and category relatedness on competitive sensemaking (Cattani, Porac, \& Thoma, 2017; Porac, Thomas, Wilson, Paton, \& Kanfer, 1995), which is further complicated in arenas with unclear boundaries. We computed the category relatedness control based on similarity of the firms' category vectors sourced from CrunchBase's list of 714 categories of products ("craft beer" and "micro-lending") and technologies ("facial recognition" and "e-signature").

Network-level controls. The number of competitive encounters in the network is conventionally included in ERGMs as a baseline "network constant" effect, similar to the intercept of a linear model. A network statistic for "geometrically weighted edgewise shared competitors" is included to control for the shared competitor distribution and prevent model degeneracy, which occurs if all ties are predicted to equal 1 or 0 (Hunter, Handcock, Butts, Goodreau, \& Morris, 2008). Additionally, the "geometrically weighted competitors" statistic is used to capture remaining Markov dependence assumptions (Lusher et al., 2013).
Finally, to account for the inertia of network evolution (cf. McKelvey, 1997), we controlled for both a linear trend in the number of encounters over time and an autoregressive network memory (Cranmer, Heinrich, \& Desmarais, 2014). For the latter effect, we used a network statistic called temporal stability, which counts the number of stable dyads (i.e., both continued rivalry and continued nonrivalry) between periods and thus controls for the persistence of absent ties-a preferable control over alternatives including temporal autocorrelation (counts only the persisting ties) and network innovation (counts only the newly created ones) (Leifeld, Cranmer, \& Desmarais, 2018). We tested for a lagged DV effect and got comparable results to temporal dyadic stability.

\section{Analyses}

An adequate profiling of indirect competitors requires methodological capabilities that are new to management research. A key problem is that relational data are necessary to capture all the awareness cues simultaneously, and yet these interdependent observations are not suited to nonrelational methods-such as ordinary least squares regression or generalized linear models-as these classic techniques assume independent observations and thus produce biased results on network data (Kim, Howard, \& Boeker, 2016; Lusher et al., 2013). Prior CD research has generally not considered a relational perspective, ignoring interdependence among variables at different levels (Contractor, Wasserman, \& Faust, 2006), so hypothesis testing retained the assumption of independent observations (a notable exception is Madhavan et al., 2004). To overcome these obstacles, we use ERGMs, which frame hypotheses in terms of the probabilities of graph realizations with specific structural tendencies (Contractor et al., 2006; on the methodological advantages of ERGMs in strategic management cf., Kim et al., 2016).

ERGMs account for network dependence and offer flexibility for defining multilevel network sufficient statistics as predictors. However, to address competitive encounters over time, our longitudinal competition network requires an extension to the ERGM specification, called temporal ERGM(TERGM) that can account for trends in factors driving competitive encounters (Hanneke, Fu, \& Xing, 2010). Hence, we use the version of TERGM described by Desmarais and Cranmer (2012) and implemented by Leifeld et al. (2018). For analyzing a hostility profile, the TERGM is preferable to the primary alternative model for longitudinal network analysis—stochastic actor-oriented model (SAOM) (Snijders, 1996)—because 
the latter's assumption of plausible connections to all nodes implies ubiquitous prior awareness and precludes application to networks larger than a few hundred nodes (Snijders, Van de Bunt, \& Steglich, 2010; for theoretical and empirical comparisons of TERGM and SAOM, cf. Leifeld \& Cranmer, 2019).

TERGM estimates are computed via maximum pseudo-likelihood estimation (MPLE) with bootstrapped confidence intervals (Desmarais \& Cranmer, 2012). Although Markov Chain Monte Carlo Maximum Likelihood Estimation (MCMLE) is a common choice for ERGM estimation in small networks (e.g., less than a few hundred nodes with only one period), it is computationally impractical for large, multiperiod networks (Schmid \& Desmarais, 2017). The MPLE is a more efficient alternative-a robust multivariate $M$-estimator for which bootstrap resampling allows consistent, unbiased confidence intervals while still avoiding the convergence issues and computational cost of MCMLE (Desmarais \& Cranmer, 2012).

Predicting individual encounters. An ERGM prescribes "how likely it is to add or delete a tie for a pair of actors given everything else" (Lusher et al., 2013: 55). This means that the log odds of a competitive encounter between firms $i$ and $j$ in period $t\left(y_{i j t}=1\right)$ are conditional on everything else-which, for a TERGM, includes not only the covariates $\boldsymbol{X}_{t}$ and model parameters $\boldsymbol{\theta}$, but also the entire remainder of the current competition network $\boldsymbol{Y}_{i j t}^{c}$ (known as the "complement of $Y_{i j t}$ ") and the past competition network $\boldsymbol{Y}_{t-1}$ :

$$
\begin{aligned}
& \operatorname{logit} \mathrm{P}\left(Y_{i j t}=1 \mid \text { "everything else" }\right)=\underbrace{\theta_{1} \delta_{i j t}\left(g_{1}\left(\text { Diversification }_{i t}\right)\right)}_{\text {firm level cue }} \\
& +\underbrace{\theta_{2} \delta_{i j t}\left(g_{2}\left(\text { AsymmetricPressure }_{i j t}\right)\right)}_{\text {dyadic level cue }}+\underbrace{\theta_{3} \delta_{i j t}\left(\text { Convergence }_{\mathrm{t}}\right)}_{\text {triadic level cue }} \\
& +\underbrace{\theta_{4} \delta_{i j t}\left(\text { Separation }_{3, t}\right)+\ldots+\theta_{K} \delta_{i j t}\left(\operatorname{Separation}_{K-1, t}\right)}_{\text {tetradic } \text { and higher level cues }}+\underbrace{\boldsymbol{\theta}_{\text {ctrl }}^{T} \delta_{i j t}\left(\mathbf{g}_{\text {ctrl }}\left(\mathbf{y}_{t}, \mathbf{y}_{t-1}, \mathbf{x}_{t}\right)\right)}_{\text {controls (all levels) }}
\end{aligned}
$$

In Equation (5), the "change statistics" $\delta_{i j t}\left(g_{r}\right)=$ $g_{r}\left(y_{i j t}=1, \mathbf{y}_{i j t}^{c}\right)-g_{r}\left(y_{i j t}=0, \mathbf{y}_{i j t}^{c}\right)$ measure the difference of the "network statistic" $g_{r}$ if the competitive encounter between dyad (ij) were to exist $\left(y_{i j t}=1\right)$ rather than not to exist $\left(y_{i j t}=0\right)$ at time $t$ (Wasserman \& Pattison, 1996). ${ }^{9}$ Each change statistic captures the amount of endogenous or exogenous dependence between the hypothesized network statistic and the network structure contributed by dyad (ij) in period $t$.

\section{RESULTS}

The results show that diversification, asymmetric pressure, convergence, and degree of separation

\footnotetext{
${ }^{9}$ Network statistics at the firm and dyad levels are created by interacting the covariate with the competitive encounters to capture dependence on the structure of competition; specifically, $g_{1}\left(\right.$ Diversification $\left._{i t}\right)=\sum_{j} y_{i j t}$ Diversification $_{i t}, \forall j \neq i$, and $g_{2}\left(\right.$ AsymmetricPressure $\left._{i j t}\right)=\sum_{i} \sum_{j} y_{i j t}$ AsymmetricPressure $_{i j t}$, $\forall j \neq i$. However, at the network levels (triad, tetrad, etc.), the awareness cues are already computed from the structure of competition, so the network statistics are defined by the awareness cues themselves (e.g., $g_{3} \equiv$ Convergence $_{t}$ ).
}

(Hypotheses 1, 2, 3a and 3b, respectively) are associated with competitive encounters; thus, all four cues define the hostility profile as predicted. We elaborate on these results below.

\section{Competition Network TERGM Hypothesis Tests}

Focusing on Qualtrics as a focal firm, Table 1 features the summary statistics and correlations for the 7,489 competitive encounters based on the network of 532 firms (2007-2016). Table 2 presents the baseline model with control variables, followed by Models 1-3 addressing all the hypotheses, and finally the full model (Model 4). Table 2 presents the TERGM coefficients' MPLE estimates with confidence intervals from 2,000 bootstrap resamples, below which we confirmed the intervals had stabilized (Leifeld et al., 2018). Effects are reported as significant when the $95 \%$ bootstrap resampled confidence interval does not contain zero.

Supporting Hypothesis 1, Model 1 (Table 2) shows that highly diversified firms face more competitive encounters compared to less diversified firms. Model 2 confirms that competitive encounters are 


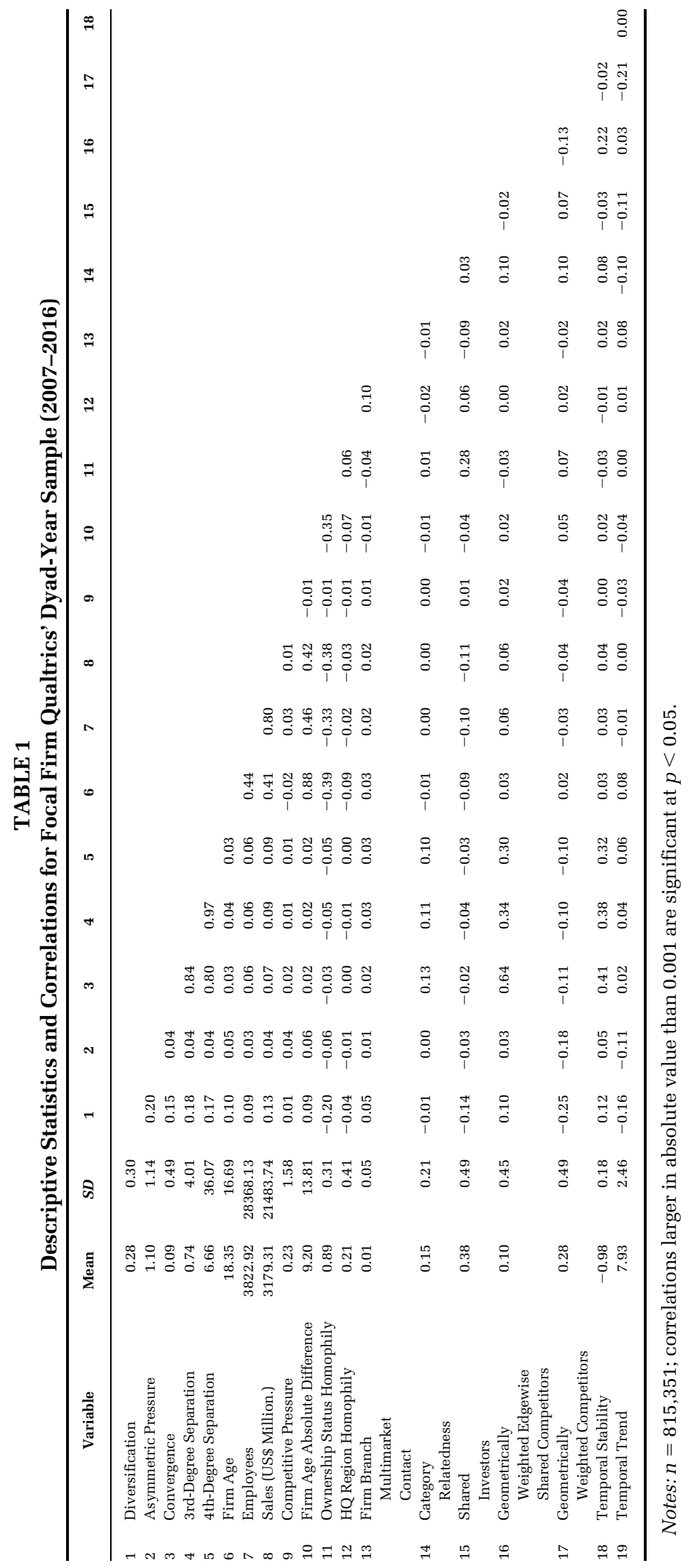




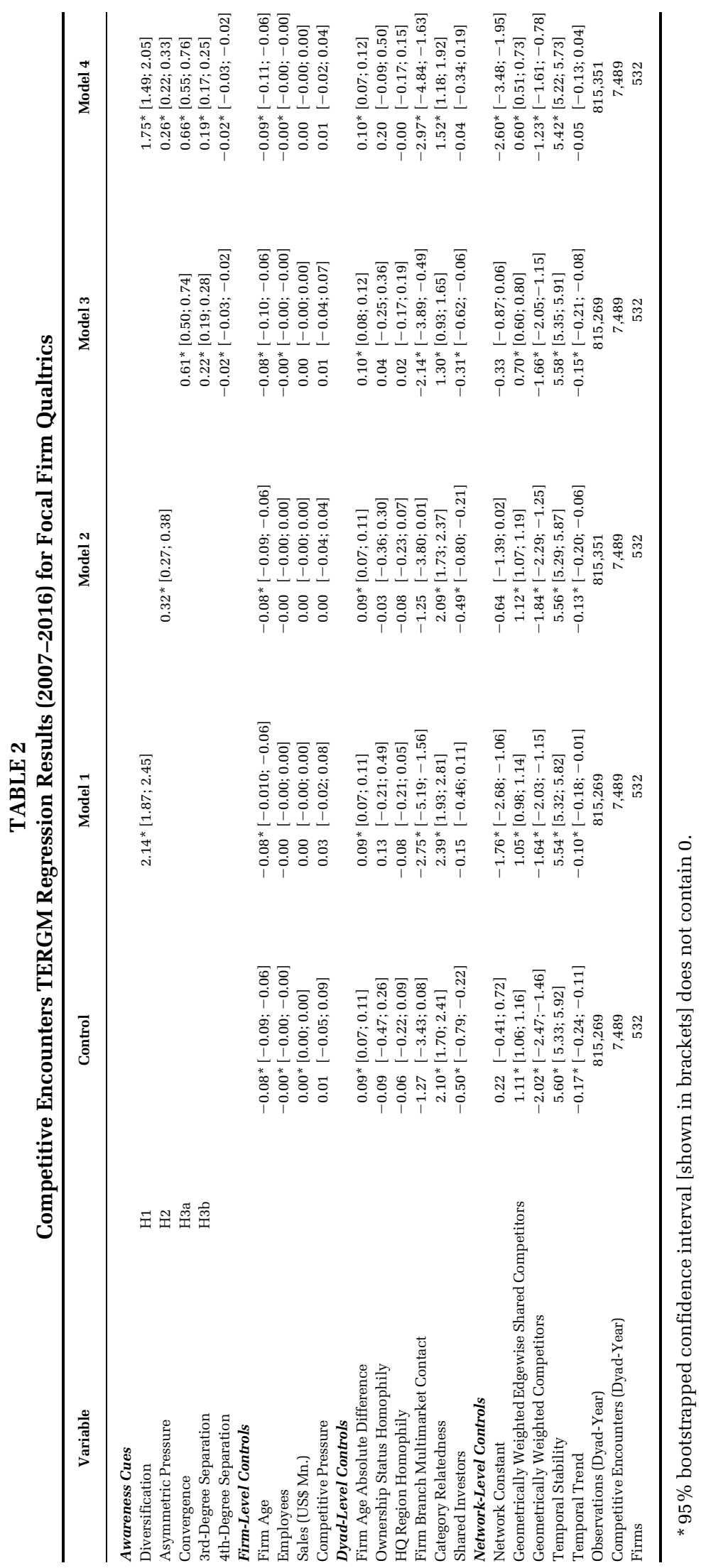


more likely among dyads with greater asymmetric pressure, thus supporting Hypothesis 2. Consistent with Hypothesis 3a, Model 3 shows that networkwide convergence is significantly related to the formation of competitive encounters. Model 3 and Model 4 (the full model) are particularly revealing for Hypothesis 3b: they show that while indirect competitors at three degrees of separation can still become direct rivals (four cycles), the greater separation between fourth-degree indirect competitors tends to have a suppressive effect on competitive encounters (five cycles). Consistent with Models 1-3, the full model (Table 2; Model 4) provides further support for all the hypotheses.

Note that caution must be taken when interpreting effect sizes for network models, since each effect is conditional on the rest of the network. Given this caveat, we offer some insight into the effect of the awareness cues. Beginning with Hypothesis 1, consider two potential competitive encounters in the network that are identical in all regards except one: diversification. One of the potential encounters involves two firms with low $\left(16^{\text {th }}\right.$ percentile) total diversification, while the other potential encounter involves two firms with high $\left(84^{\text {th }}\right.$ percentile) total diversification. According to Equation (5), depending on the rest of the network and assuming controls equal their median values, the difference in diversification would be associated with a $172 \%$ increase in the probability of the high-diversification encounter occurring over the low-diversification alternative, on average. If the focal firm were a party in both these potential encounters, then it might interpret this difference as the increased likelihood of encountering the high-diversification indirect competitor. Applying the same cautious interpretation and assumptions for Hypothesis 2, the difference from low to high asymmetric pressure between two (otherwise identical) potential encounters would be associated with an $80 \%$ increase in the probability of the high-asymmetry encounter occurring, on average. Finally, considering the network-level cues (Hypothesis 3), we interpret the difference between two potential encounters that would create zero versus one rivalry cycles for convergence (three cycles), third-degree separation (four cycles), and fourth-degree separation (five cycles). These would be associated with an $84 \%$ increase, $24 \%$ increase, and $2 \%$ decrease, respectively, in the likelihood of the structurally endogenous encounter occurring, relative to the alternative encounter that would not contribute to landscape substructural dynamics.
The results reveal that third-degree indirect competitors-the rivals of a focal firm's direct rivals' rivals-represent the "Ultima Thule" (i.e., the outer bounds) within which indirect competitors become direct rivals. After three degrees of separation (four cycles), the association is either negative (fourthdegree separation suppresses five-cycle encounters) or no longer significant (fifth-degree or higher separation has no association with randomly occurring six-cycle or higher encounters). Put in conceptual terms, CD scholars can see-for the first time-a well-defined hostility profile in which competition ensues and beyond which it does not. The hostility profile entails direct rivals (of course), and up to and including third-degree indirect competitors. The profile uncovers a separation bound: After three degrees of separation, the negative or insignificant association does not merit awareness for competitive encounters. As expected, the effect of the degree of separation decreases with increased length of cycles, from three cycles to four cycles to five cycles. Thus, expanding awareness up to and including third-degree indirect competitors makes sense, but beyond that point the dearth of threat from more separated players would render awareness impractical.

Adding precision to guide scholarly research and managerial action, Figure 3 features the competition network of Qualtrics in 2008 and 2016, with quadrants $A$ and $B$ featuring aerial maps, and quadrants $C$ and $D$ showing segmentation graphs by a degree of separation. In quadrants $A$ and $B$, the blue square presents Qualtrics while red circles represent its competitive threats-firms with sufficiently high probability of forming competitive encounters with Qualtrics. Unfilled circles show all other firms considered less threatening. An interesting insight from these aerial maps is that some adjacent firms may remain nonrivals despite their tight proximity to the focal firm, even when convergence causes distant indirect competitors to become direct rivals. The visual depiction corroborates that convergence and degree of separation play distinct roles.

To further elaborate on competitive threats, quadrants $C$ and $D$ use a degree of separation "filter" that segments competitive threats into four group types: direct rivals, expected indirect competitors, unexpected indirect competitors, and nonrivals. Direct rivals (one degree of separation) already engage the focal firm so they require no elaboration. At two degrees of separation, we find indirect competitors whose threat may be expected because of transitive 
FIGURE 3

Aerial Maps and Segmentation Graphs of Competitive Threats over Time

2008

A

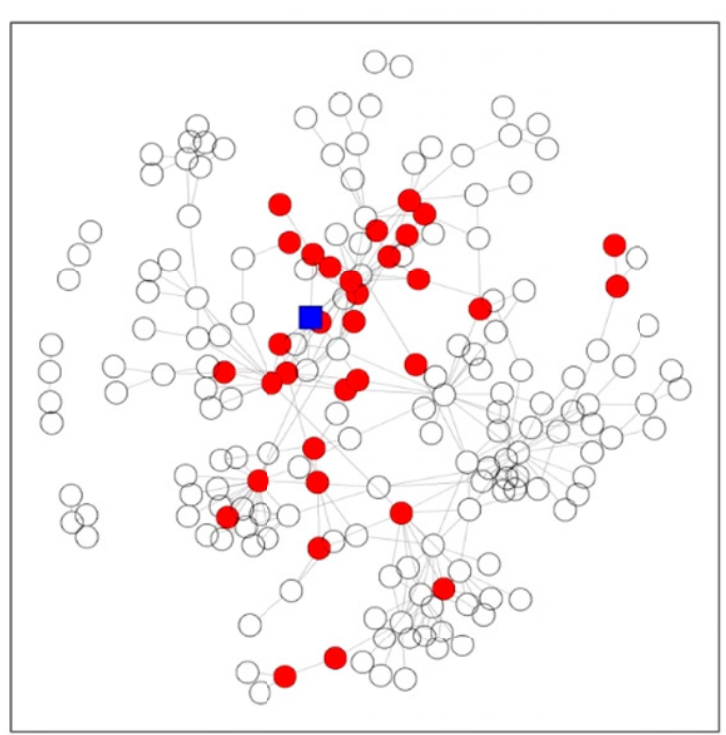

Focal Firm

Competitive Threats

All Other Firms
2016

B

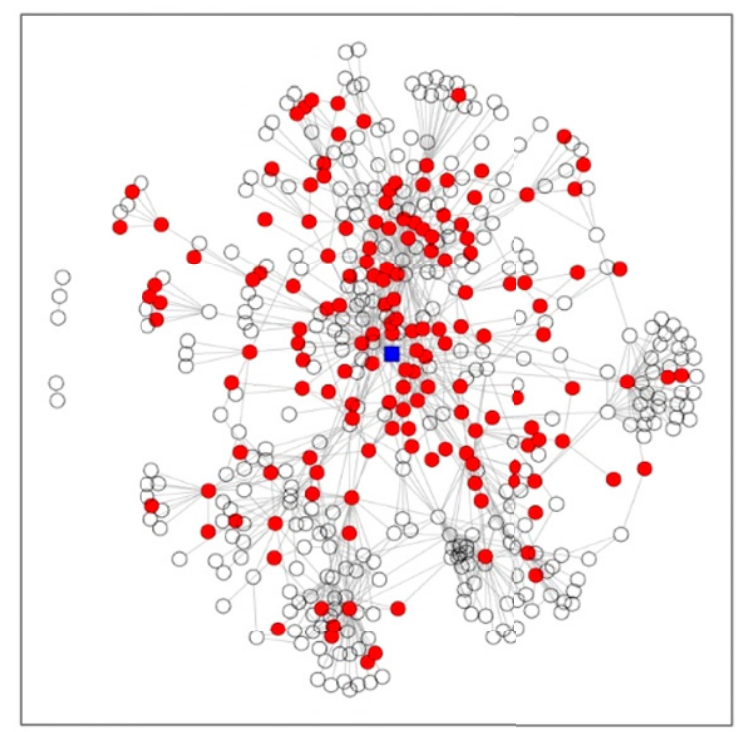

Focal Firm Competitive Threats $\bigcirc$ All Other Firms
2008

\section{C}

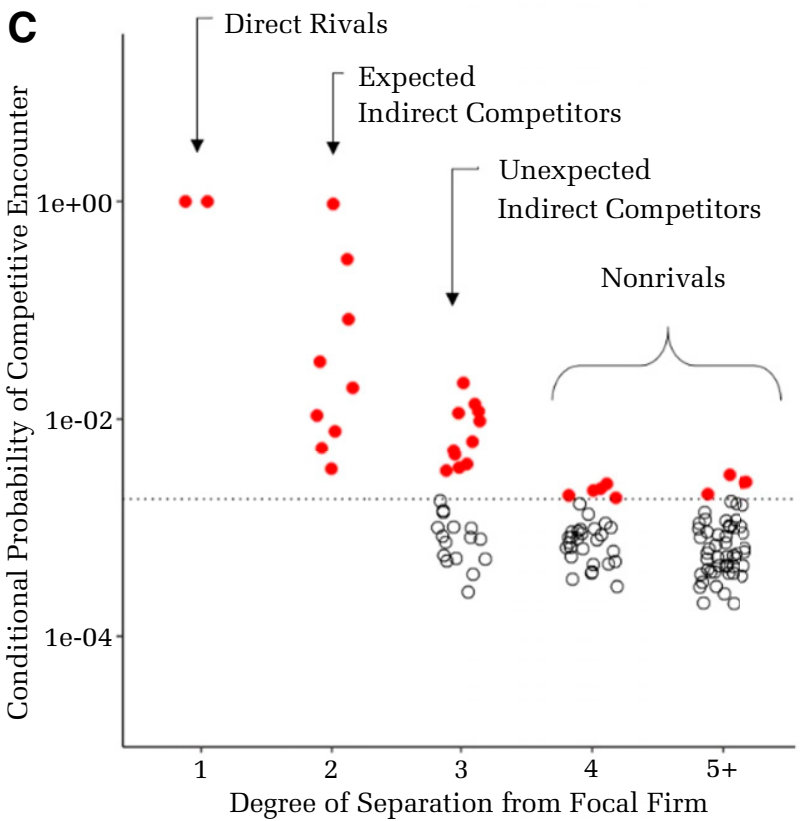

Segmentation Graphs

2016

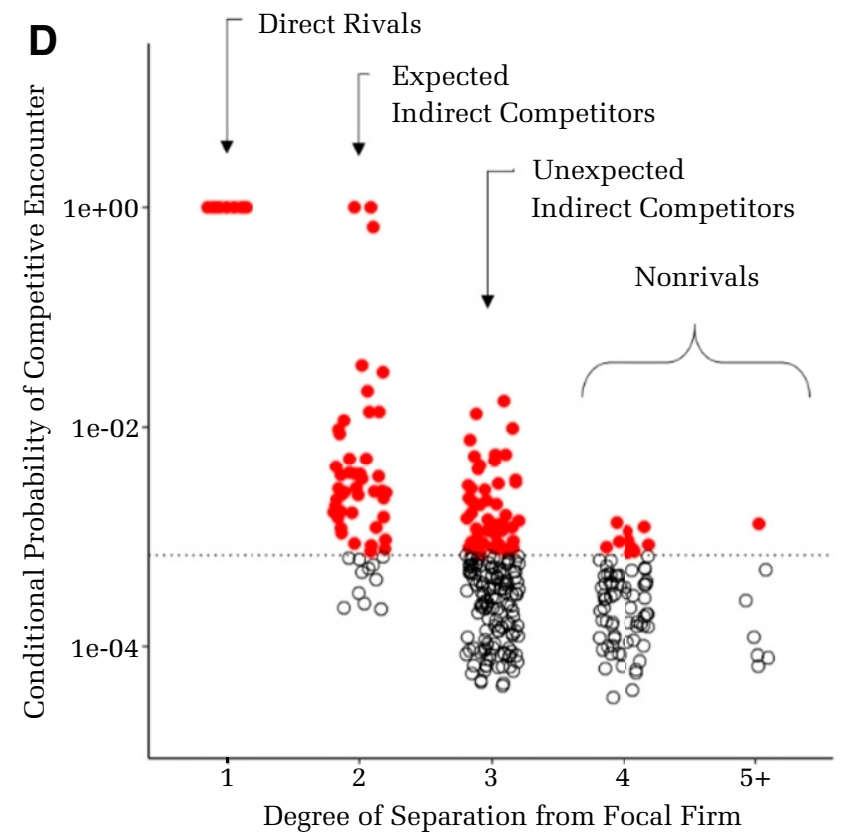

Notes: Quadrants $A$ and $B$ show aerial maps of Qualtrics (blue) and its rivals and indirect competitors, who are identified as the competitive threats (red), meaning firms with high conditional probability of competitive encounters in 2008 and 2016. Quadrants $C$ and $D$ present the conditional probabilities of competitive encounter ( $y$-axis) and degree of separation ( $x$-axis) for firms in the corresponding early period (quadrant $C, 2008$ ) and late period (quadrant $D, 2016$ ). The firms that fit the hostility profile (red) in quadrants $C$ and $D$ encompass four distinct segments: direct rivals (firms at one degree of separation from Qualtrics); expected indirect competitors (two degrees of separation); unexpected indirect competitors (three degrees of separation), and nonrivals (more than three degrees; firms that, on average, have little chance to encounter Qualtrics). Note that the distribution of firms in each degree segment changes over time as the competition network evolves. 
convergence (Hypothesis 3a). Unexpected indirect competitors, a group that CD research has tended to overlook, are found at three degrees of separation. As the network structure is conducive to convergence, and indirect competitors still have a significant probability of becoming direct rivals, this group of firms (third-degree indirect competitors) poses the highest blindsiding threat. Finally, at four or more degrees of separation are the bona fide nonrivals, who do not merit awareness since they, on average, have no significant path to the focal firm. Because nonrivals are beyond the threshold at which indirect competitors become direct rivals, the hostility profile reveals they merit little attention. In addition, from quadrants $C$ to $D$, the crowding effect shows that distant indirect competitors come closer to the focal firm and quite a few become direct rivals.

\section{Goodness of Fit}

The assessment of goodness of fit (GOF), which tests whether the observed data match the theoretical predictions, is a protracted, rigorous process for ERGMs that aims to capture the corresponding endogenous dependencies in the full model (cf., Desmarais \& Cranmer, 2012; Hunter et al., 2008; Leifeld et al., 2018). To this end, we simulated 10,000 random networks from the parameters and covariates of the full model (Model 4), then used auxiliary statistics computed from this simulated sample as a baseline for comparison with the observed network statistics, again from the full model. If the observed network statistics align with the statistics computed from the sample of random networks, then the model is a good fit. The simulated distributions of "dyadwise shared competitors," "edgewise shared competitors," and "degree” (i.e., number of competitors) each revealed a good fit with our model, both in terms of a visual assessment of GOF plots (available upon request) and tests of group means: the simulated frequencies of each value (ranging from 0 to 16) of each auxiliary statistic confirm the similarity between the simulated and observed network with a significance level of 0.05 . Finally, the auxiliary statistic of "geodesic distance" (i.e., lowest degree of separation) is also a very good fit in the range that is our focus (path lengths up to 11); none are significantly different from the simulated sample. To recap, the GOF assessment shows that our full model adequately reproduces networks similar to the observed data within the range of the auxiliary statistic distributions that are relevant for our focal firm's competition network.

\section{Robustness Checks}

Adding a layer of rigor, we conducted five robustness checks as detailed below (see Appendix A, Tables A1-A4).

Model reproducibility. The use of a single focal firm suits the task of competitor identification, but raises concerns about the reproducibility and generalizability of the results for other firms. To address this, we created competition networks for 24 other focal firms (25 in total) that were rivals or competitive threats of the first, then recomputed Model 4 for each of these new focal-firm competition networks (Table A1). Hypothesis 1, Hypothesis 3a, and Hypothesis $3 \mathrm{~b}$ are consistent in sign and significance for all 25 networks (100\%), and Hypothesis 2 for 24 of the networks (96\%).

Diversification. We used the multilevel network community algorithm (Blondel, Guillaume, Lambiotte, \& Lefebvre, 2008) to capture the degree of diversification across firms with the hierarchical distinction between inter- and intraspace ties. Five other community algorithms were also tested (see Table A2). Although they differ in the number of network communities identified, the diversification values computed from these community membership outputs were all consistent with our measures.

Asymmetric pressure. The computation of differential exposure to competitive pressure includes each firm's competitive pressure, which requires setting the decay parameter $(\beta)$ that controls how distant effects impact firms. Primary results in Table 2 use a distant network effect setting: $\beta=-0.4$. Since the results may be sensitive to this setting, we reran TERGM Model 4 for the focal firm using the other values from Bonacich (1987) that are also theoretically suitable for a competition network $(-0.1,-0.2,-0.3,-0.5$; see Table A3). The results of all hypotheses are unchanged in sign and significance regardless of the competitive pressure decay $\beta$ used. ${ }^{10}$

Degree of separation. We checked the effect of a lower degree of separation threshold for competition network cohort selection by reselecting the cohort using a threshold of two degrees of separation (instead of three) and then recomputed Model 4. As Table A4 shows, the signs and significance of all hypotheses remained unchanged despite including

\footnotetext{
${ }^{10}$ The lower 95\% confidence bound of asymmetric pressure decreases (approaching zero) for smaller absolute values of $\beta$, capturing less-distant effects, which supports our use of a distant network effect setting for $\beta$.
} 
fewer firms (168 down from 532). Importantly, this indicates that all awareness cues are robust to the choice of threshold used in cohort selection; each firm's threshold should suit its own resources and environment. However, there is still a limit to the degree of separation firms need to consideradditional analyses on larger $k$-cycles show that the convergent effect has completely dissipated by five degrees of separation (note the insignificant effects for six cycles and higher).

Cooperative relations. Finally, checking the effect of cooperation on competition (Sytch \& Tatarynowicz, 2014), we retested Model 4 while controlling for cooperative ties (alliances and joint ventures). As expected, the cooperative relation effect is negative (i.e., suppressing competitive encounters). However, this did not change the hypotheses; all remained significant.

The consistency and reproducibility of the results through the GOF tests and five robustness checks are remarkable, but of course more research is needed before our hostility profile is deemed empirically generalizable and theoretically robust.

\section{DISCUSSION}

Early detection of competitive threats is hardly a new imperative; yet, even under static market conditions, spotting rivals before they strike is not a trivial task, especially with the fungibility of technology; the blending of business, politics, and society; and the formation of new business models and multisided platforms. Still, those who can see farther are better positioned to preempt, ally with, retreat, defend against, or ignore would-be rivals in accordance with their best interests. Following the doctrine that the enemy of my enemy is my friend, CD research enhances our awareness of direct rivals (Chen \& Miller, 2012), but the ability to see which indirect competitors are poised to become direct rivals has remained underdeveloped. How, then, can the awareness construct-the first in the AMC framework-become more revelatory? To address this question, we constructed competition networks from six data sources to analyze 15,824,693 observations in the CEM arena over a 10-year period (2007-2016). Of these, 142,446 were competitive encounters between 25 focal firms and their

FIGURE 4

Awareness Cues and Shifting Theoretical Perspectives on Competitor Identification

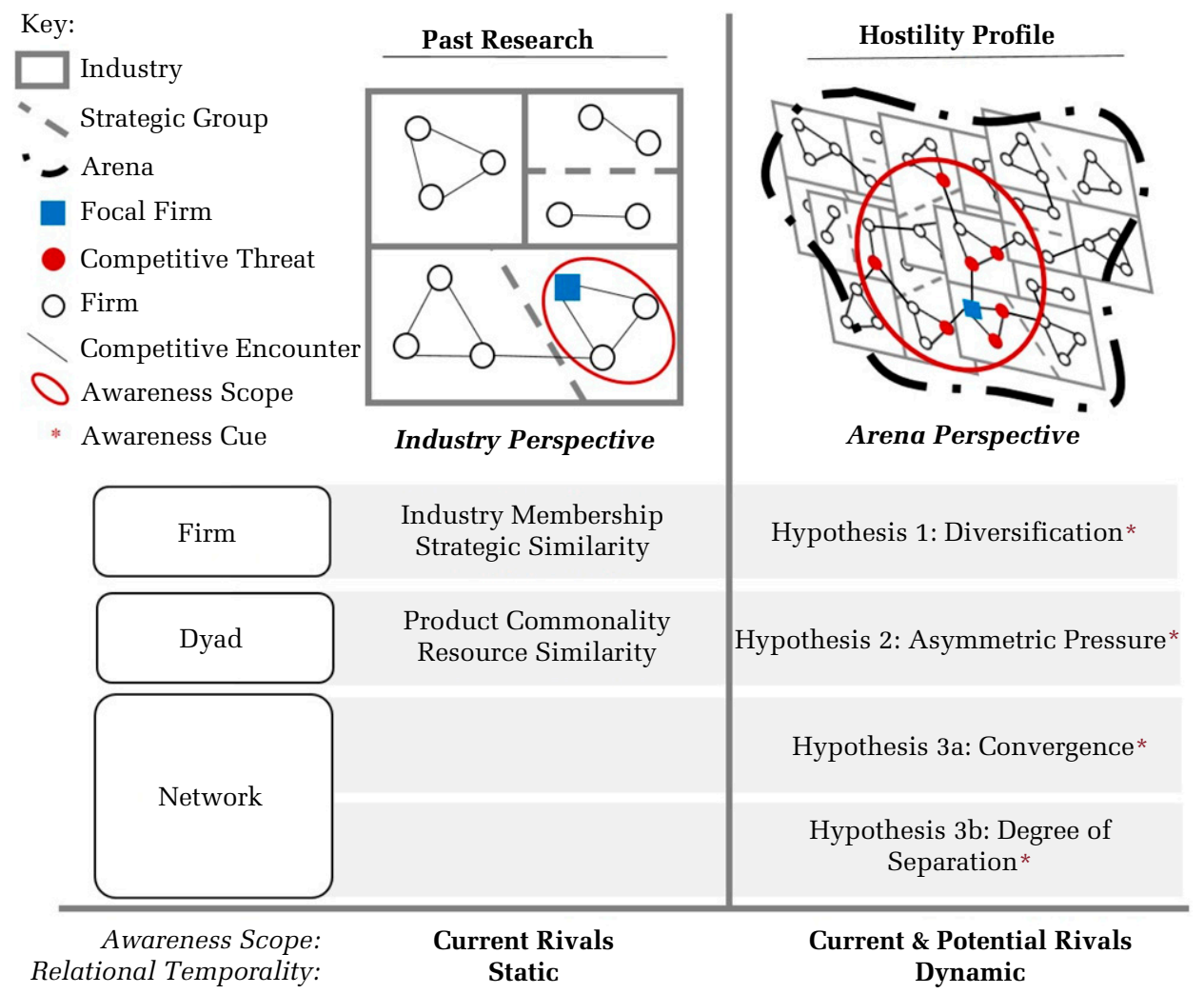


respective 10,257 direct and indirect competitors (2,920 unique firms).

Our profiling approach, datasets, and novel methodology allow us to see further, and hence make several contributions to the SRF "New Ways of Seeing." First, as noted above, past studies have used an industry prism and assumed that (i) firms compete inside, but hardly across, their industry precincts (Chen \& Miller, 2012; Gur \& Greckhamer, 2019); and (ii) the awareness construct is mostly for considering existing rivals, so indirect competitors have rarely been profiled (Chen \& Miller, 2015). Challenging these dogmas, we use an arena view to capture crossindustry movement and competitive encounters that have been overlooked in the past. In addition, acknowledging the fact that rivals are embedded in dyads, triads, tetrads, etc., we develop a multilevel hostility profile that classifies indirect competitors according to their likelihood of becoming direct rivals.

Second, the hostility profile signifies consensusshifting theorizing in CD research, as it proffers a predictive awareness construct. Specifically, we shift the focus from static, direct rivals within a single industry to include indirect competitors who cross industry precincts, and from relying on reactive awareness to having well-defined conditions under which competitive encounters ensue (and do not ensue). These conditions include (i) when a focal firm or its indirect competitors are highly diversified, (ii) when a dyad's asymmetric pressure is high, (iii) when networks are converging, and (iv) when the degree of separation between firms is three or less. Although most threats come from direct rivals and proximal indirect competitors, topographical proximity alone cannot predict competitive encounters, but the concomitant application of all multilevel awareness cues can. The degree of separation threshold presents a boundary condition on the hostility profile for how far-in terms of network rungs-a focal firm should allocate awareness to indirect competitors (answer: up to third-degree indirect competitors). Returning to the "the enemy of my enemy is my friend" doctrine, in the CEM arena (i) the enemy of my enemy is often my enemy, (ii) the enemy of my enemy's enemy can still be my enemy, but (iii) the enemy of my third-degree indirect enemy is unlikely to be my enemy. Thus, the awareness cues and resulting hostility profile proffer a more predictive AMC framework.

To clarify how the hostility profile advances the SRF and affords a new way of seeing, Figure 4 unpacks these contributions in the context of past research. Going from left to right and top to bottom, past research has followed an industry view (e.g., market commonality and resource similarity prescriptions) to study existing, direct rivals. By contrast, our study takes an arena view to profile indirect competitors before hostility ensues. Past studies have focused primarily on firm- and dyad-level encounters, but ours complements such work with a network perspective that accounts for multisided competition. To illustrate this point, consider the classification of rivals as complementors, substitutors, suppliers, new entrants, and so on (Peteraf \& Bergen, 2003). Such labels are certainly helpful, yet they do not reveal which entity stands to become a direct rival. Our study provides the theory and methodology to see which complementor (out of many) might become a direct rival, or whether "Substitutor A" poses a greater threat compared to "Supplier B." The hostility profile builds on and goes beyond role classification as it guides firms and scholars to triage threats according to the probability of competitive encounters.

The introduction of the TERGM to address interdependent observations and their changes over time constitutes a methodological contribution. While relational data are necessary to capture all awareness cues simultaneously, extant empirical research has ignored the interdependence of numerous drivers of interfirm encounters (Kim et al., 2016). Consequently, the reliance on nonrelational methods and single-level analysis has missed important insights about interfirm relations and how landscape structures emerge (Contractor et al., 2006). Our multilevel, network-centric approach overcomes such limitations by explicitly modeling both exogenous and endogenous dependencies among substructures of competitive landscapes to reveal which indirect competitors are likely to become direct rivals. The magnitude, span, scope, and granularity of our study (i.e., 15,824,693 observations, containing 142,446 competitive encounters, over a 10 -year period and 29 SIC codes) plus the five robustness checks and TERGM methodology are quite reassuring. Furthermore, in contrast to many CD studies that have oversampled public companies while deemphasizing entrepreneurial firms, our multisource dataset is more inclusive and quite representative of the typical private-public ratio ( $94 \%$ vs. $6 \%$ ). Naturally, the robustness of the hostility profile across time and competitive arenas calls for further research, which we address below.

\section{Future CD Research}

As with most studies, ours has certain limitations that create opportunities for further CD research and 
for advancing the wider domain of management. First, our findings are based on one, albeit diverse, competitive arena (i.e., CEM), and though the setting afforded new insights on a mixture of mostly private and a few public firms, future research should investigate the generalizability of the hostility profile in other arenas. For instance, Markman, Waldron, and Panagopoulos (2016) noted that some of the most blindsiding attacks come not from traditional rivals but from nonmarket players-e.g., activists and nongovernmental organizations. Future studies could examine whether different players and arenas require distinctly different hostility profiles. Second, our analyses reveal that some indirect competitors in one period became direct rivals a year or two later, suggesting that future research could clarify the timing of competitive engagements. Even if the AMC framework adopted the hostility profile, it would still struggle to time competitive encounters, so exploring modalities to measure how long it takes for an indirect competitor to become a direct rival would surely advance the hostility profile.

A third area for future scholarship is for the AMC framework to predict collaborative ties. To offer examples, alliances, buyer-supplier partnerships, and joint ventures represent movements that alter network morphology, so scholars could develop cooperation profiles (demarcated areas within which focal firms might select their most fitting allies and partners). This would represent a valuable scholarly effort as the proliferation of alliances (some firms are members of 30-60 alliances) and the high failure rate $(60-70 \%)$ suggest that, despite their cooperative aura, many alliances are also contentious (Hughes \& Weiss, 2007). Alliances and partnerships represent a context that entails both collaboration and competition (Sonenshein, Nault, \& Obodaru, 2017; Sytch \& Tatarynowicz, 2014), yet CD research and studies on collaboration have rarely considered each other (a notable exception is Chen \& Miller, 2015). This could be a fruitful area for profiling research. The core point: Just as the hostility profile nuances the AMC framework, scholars can use our profiling principles to nuance diverse dependent variables and make theories more predictive.

\section{Implications for the Broader Domain of Management}

As a profiling study, our research underscores the need to apply a wider, farther, and better-calibrated view of phenomena in competitive landscapes (Levitt, 1960). Addressing the challenge of distant foresight (Gavetti, 2012) to redress competitive myopia, profiling studies can employ our approach to offer a cognitive representation to understand complex, interdependent arenas. Indeed, the aerial maps we featured (Figure 3) are akin to the cognitive maps that managers employ in forward-looking search processes (Gavetti \& Levinthal, 2000), and aid in tracking threats and opportunities over time. Exemplifying this landscape complexity, a technology lens-like an arena view-offers perspectives across and beyond the boundaries of firms, markets, and industries, so it can assist with profiling diverse management phenomena. To illustrate the "blendification" of technologies, markets, and industries, consider how clothing companies embed nanosensors that collect and emit a slew of predictive health data (e.g., heart rate, insulin levels, etc.) while supply-chain firms use artificial intelligence to monitor and predict the operations and throughput from raw resource providers to assembly lines and then to consumers. We use these examples to show that as technology becomes more fungible, scholars will need better profiling modalities to analyze and predict diverse cause-effect relations.

Reflecting on the allocation of attentional resources, our treatment of awareness is complementary to attention-based view (ABV) research (Ocasio, 1997). The ABV literature has explained that firms fail to detect threats and prevent calamities not because of an absence of signals or insufficient knowledge (or faulty awareness), but because attention bandwidth and information-processing fidelity are inherently limited (March \& Simon, 1958; Ocasio, 1997; Ocasio, Laamanen, \& Vaara, 2018). Misalignment between the granularity of managerial attention and the scale of a threat can also cause attention failure-e.g., firms might obtain a better view by applying either finegrained attention to study small-scale threats or broad attention to look at large-scale threats (Bansal et al., 2018). Restricted information processing and signalreceiver misalignment certainly erode managerial attention (McMullen, Shepherd, \& Patzelt, 2009; Vuori \& Huy, 2016), but that is why research on profiling modalities-to better define where to look, what to search for, and how to decode signals-can ameliorate attention and signal-receiver limitations. Continued research into profiling modalities may afford boundary-expanding foresights to see around corners. Scholars could advance predictive profiling techniques to match resources or capabilities with opportunities, to foretell which entrants merit collaboration, and to vet allies and suppliers. 
Profiling studies should also set clear boundary conditions-e.g., in our sample, indirect competitors who are four or more degrees of separation removed from a focal firm require no awareness. Profiling approaches have also been applied to market opportunity choice sets (Gruber, MacMillan, \& Thompson, 2008; Gruber et al., 2013) or opportunity spaces (Kornish \& Ulrich, 2011; Terwiesch \& Ulrich, 2009) to better define and prioritize a range of promising venture ideas, scope the benefits and risks related to potential business models, and foretell growth options for established firms. The challenge, of course, is that the dimensions and boundaries of opportunity spaces and antecedents of great versus average opportunities are not defined well enough. Therefore, scholars might borrow the same logic used in our study to better triangulate opportunity spaces. The lesson to the extant management discipline is that when studies expand theory while also defining boundary conditions, they stand to make more lasting contributions.

\section{CONCLUSION}

Despite substantive changes in how firms compete and industries morph-combined with major methodological advancements-the awareness construct in the AMC framework has remained myopic. Using an arena view to account for firm movement across industries, we identified four awareness cues that together define a hostility profile and make the awareness construct more prescient. The hostility profile is based on diversification (a firm-level cue), asymmetric competitive pressure (at the dyad level), and the convergence of landscapes and degree of separation between firms (both network-level cues), and predicts which indirect competitors are poised to become direct rivals. We also showed that only direct rivals and second- and third-degree indirect competitors are revealed to be competitive threats by the hostility profile, thus meriting awareness (fourthdegree indirect players and beyond do not). Overall, our study provides theoretical and empirical refinements to the construct and application of awareness, thus affording scholars and firms a new way of seeing competitive threats.

\section{REFERENCES}

Bansal, P., Kim, A., \& Wood, M. O. 2018. Hidden in plain sight: The importance of scale in organizations' attention to issues. Academy of Management Review, 43: 217-241.
Baum, J. A. C., \& Korn, H. J. 1996. Competitive dynamics of interfirm rivalry. Academy of Management Journal, 39: 255-291.

Baum, J. A. C., \& Korn, H. J. 1999. Dynamics of dyadic competitive interaction. Strategic Management Journal, 20: 251-278.

Bennett, V. M., \& Pierce, L. 2016. Motivation matters: Corporate scope and competition in complementary product markets. Strategic Management Journal, 37: 1304-1315.

Blondel, V. D., Guillaume, J.-L., Lambiotte, R., \& Lefebvre, E. 2008. Fast unfolding of communities in large networks. Journal of Statistical Mechanics, 10: P10008.

Bonacich, P. 1987. Power and centrality: A family of measures. American Journal of Sociology, 92: 1170-1182.

Borgatti, S. P., \& Lopez-Kidwell, V. 2011. Network theory. In J. Scott \& P. J. Carrington (Eds.), The SAGE handbook of social network analysis: 40-54. London, U.K.: SAGE publications.

Butts, C. T. 2006. Cycle census statistics for exponential random graph models. Retrieved from UC Irvine: Institute for Mathematical Behavioral Sciences. Retrieved from https://escholarship.org/uc/item/4719h8d2.

Cattani, G., Porac, J. F., \& Thoma, H. 2017. Categories and competition. Strategic Management Journal, 38: 64-92.

Chen, M.-J. 1996. Competitor analysis and interfirm rivalry: Toward a theoretical integration. Academy of Management Review, 21: 100-134.

Chen, M.-J., \& Hambrick, D. C. 1995. Speed, stealth, and selective attack: How small firms differ from large firms in competitive behavior. Academy of Management Journal, 38: 453-482.

Chen, M.-J., \& Miller, D. 2012. Competitive dynamics: Themes, trends, and a prospective research platform. Academy of Management Annals, 6: 135-210.

Chen, M.-J., \& Miller, D. 2015. Reconceptualizing competitive dynamics: A multidimensional framework. Strategic Management Journal, 36: 758-775.

Chen, M.-J., Su, K.-H., \& Tsai, W. 2007. Competitive tension: The awareness-motivation-capability perspective. Academy of Management Journal, 50: 101-118.

Clauset, A., Newman, M. E. J., \& Moore, C. 2004. Finding community structure in very large networks. Physical Review. E, 70: 066111.

Connelly, B. L., Lee, K. B., Tihanyi, L., Certo, S. T., \& Johnson, J. L. 2019. Something in common: Competitive dissimilarity and performance of rivals with common shareholders. Academy of Management Journal, 62: 1-21.

Contractor, N. S., Wasserman, S., \& Faust, K. 2006. Testing multitheoritical, multilevel hypotheses about organizational networks: An analytic framework and empirical example. Academy of Management Review, 31: 681-703. 
Cook, K. S., \& Emerson, R. M. 1978. Power, equity and commitment in exchange networks. American Sociological Review, 43: 721-739.

Cook, K. S., Emerson, R. M., Gillmore, M. R., \& Yamagishi, T. 1983. The distribution of power in exchange networks: Theory and experimental results. American Journal of Sociology, 89: 275-305.

Cranmer, S. J., Heinrich, T., \& Desmarais, B. A. 2014. Reciprocity and the structural determinants of the international sanctions network. Social Networks, 36: $5-22$.

Dattée, B., Alexy, O., \& Autio, E. 2018. Maneuvering in poor visibility: How firms play the ecosystem game when uncertainty is high. Academy of Management Journal, 61: 466-498.

D’Aveni, R. A. 2002. Competitive pressure systems: Mapping and managing multimarket contact. MIT Sloan Management Review, 44: 39-49.

Davis, G. F., Diekmann, K. A., \& Tinsley, C. H. 1994. The decline and fall of the conglomerate firm in the 1980s: The deinstitutionalization of an organizational form. American Sociological Review, 59: 547-570.

Delios, A., \& Beamish, P. W. 1999. Geographic scope, product diversification, and the corporate performance of Japanese firms. Strategic Management Journal, 20: 711-727.

Desarbo, W. S., Grewal, R., \& Wind, J. 2006. Who competes with whom: A demand-based perspective for identifying and representing asymmetric competition. Strategic Management Journal, 27: 101-129.

Desmarais, B. A., \& Cranmer, S. J. 2012. Statistical mechanics of networks: Estimation and uncertainty. Physica A, 391: 1865-1876.

Freeman, J., Carroll, G. R., \& Hannan, M. T. 1983. The liability of newness: Age dependence in organizational death rates. American Sociological Review, 48: 692-710.

Gargiulo, M., Ertug, G., \& Galunic, C. 2009. The two faces of control: Network closure and individual performance among knowledge workers. Administrative Science Quarterly, 54: 299-333.

Gavetti, G. 2012. Perspective-Toward a behavioral theory of strategy. Organization Science, 23: 267-285.

Gavetti, G., \& Levinthal, D. 2000. Looking forward and looking backward: Cognitive and experiential search. Administrative Science Quarterly, 45: 113-137.

Gimeno, J. 2004. Competition within and between networks: The contingent effect of competitive embeddedness on alliance formation. Academy of Management Journal, 47: 820-842.

Gimeno, J., \& Woo, C. Y. 1999. Multimarket contact, economies of scope, and firm performance. Academy of Management Journal, 42: 239-259.
Girma, S., Greenaway, D., \& Kneller, R. 2003. Export market exit and performance dynamics: A causality analysis of matched firms. Economics Letters, 80: 181-187.

Gnyawali, D. R., \& Madhavan, R. 2001. Cooperative networks and competitive dynamics: A structural embeddedness perspective. Academy of Management Review, 26: 431-445.

Granovetter, M. S. 1973. The strength of weak ties. American Journal of Sociology, 78: 1360-1380.

Gruber, M., MacMillan, I. C., \& Thompson, J. D. 2008. Look before you leap: Market opportunity identification in emerging technology firms. Management Science, 54: 1652-1665.

Gruber, M., MacMillan, I. C., \& Thompson, J. D. 2013. Escaping the prior knowledge corridor: What shapes the number and variety of market opportunities identified before market entry of technology start-ups? Organization Science, 24: 280-300.

Gulati, R., \& Gargiulo, M. 1999. Where do interorganizational networks come from? American Journal of Sociology, 104: 1439-1493.

Gulati, R., \& Sytch, M. 2007. Dependence asymmetry and joint dependence in interorganizational relationships: Effects of embeddedness on a manufacturer's performance in procurement relationships. Administrative Science Quarterly, 52: 32-69.

Guo, W., Yu, T., \& Gimeno, J. 2017. Language and competition: Communication vagueness, interpretation difficulties, and market entry. Academy of Management Journal, 60: 2073-2098.

Gur, F. A., \& Greckhamer, T. 2019. Know thy enemy: A review and agenda for research on competitor identification. Journal of Management, 45: 20722100.

Haleblian, J. J., McNamara, G., Dykes, B. J., \& Kolev, K. 2012. Exploring firm characteristics that differentiate leaders from followers in industry merger waves: A competitive dynamics perspective. Strategic Management Journal, 33: 1037-1052.

Hanneke, S., Fu, W., \& Xing, E. P. 2010. Discrete temporal models of social networks. Electronic Journal of Statistics, 4: 585-605.

Haveman, H. A., \& Nonnemaker, L. 2000. Competition in multiple geographic markets: The impact on growth and market entry. Administrative Science Quarterly, 45: 232-267.

Headd, B. 2003. Redefining business success: Distinguishing between closure and failure. Small Business Economics, 21: 51-61.

Hsieh, K.-Y., Tsai, W., \& Chen, M.-J. 2015. If they can do it, why not us: Competitors as points for justifying escalation of commitment. Academy of Management Journal, 58: 38-58. 
Hsieh, K.-Y., \& Vermeulen, F. 2014. The structure of competition: How competition between one's rivals influences imitative market entry. Organization Science, 25: 299-319.

Hughes, J., \& Weiss, J. 2007. Simple rules for making alliances work. Harvard Business Review, 85: 122-126.

Hunter, D. R., Handcock, M. S., Butts, C. T., Goodreau, S. M., \& Morris, M. 2008. ergm: A package to fit, simulate and diagnose exponential-family models for networks. Journal of Statistical Software, 24: 1-29.

Kim, J. Y. R., Howard, M., \& Boeker, W. 2016. Understanding network formation in strategy research: Exponential random graph models. Strategic Management Journal, 37: 22-44.

Korn, H. J., \& Baum, J. A. C. 1999. Chance, imitative, and strategic antecedents to multimarket contact. Academy of Management Journal, 42: 171-193.

Kornish, L. J., \& Ulrich, K. T. 2011. Opportunity spaces in innovation: Empirical analysis of large samples of ideas. Management Science, 57: 107-128.

Kryscynski, D., \& Ulrich, D. 2015. Making strategic human capital relevant: A time-sensitive opportunity. Academy of Management Perspectives, 29: 357-369.

Leifeld, P., \& Cranmer, S. J. 2019. A theoretical and empirical comparison of the temporal exponential random graph model and the stochastic actor-oriented model. Network Science, 7: 20-51.

Leifeld, P., Cranmer, S. J., \& Desmarais, B. A. 2018. Temporal exponential random graph models with btergm: Estimation and bootstrap confidence intervals. Journal of Statistical Software, 83: 1-36.

Levitt, T. 1960. Marketing myopia. Harvard Business Review, 38: 45-56.

Li, D., Eden, L., Hitt, M. A., \& Ireland, R. D. 2008. Friends, acquaintances, or strangers? Partner selection in $\mathrm{R} \& \mathrm{D}$ alliances. Academy of Management Journal, 51: 315-334.

Lusher, D., Koskinen, J., \& Robins, G. 2013. Exponential random graph models for social networks: Theory, methods, and applications. New York, NY: Cambridge University Press.

Madhavan, R., Gnyawali, D. R., \& He, J. 2004. Two's company, three's a crowd? Triads in cooperativecompetitive networks. Academy of Management Journal, 47: 918-927.

Manral, L., \& Harrigan, K. R. 2018. The logic of demandside diversification: Evidence from the US telecommunications sector, 1990-1996. Journal of Business Research, 85: 127-141.

March, J. G. 1991. Exploration and exploitation in organizational learning. Organization Science, 2: 71-87.
March, J. G., \& Olsen, J. P. 1976. Organizational choice under ambiguity. Ambiguity and Choice in Organizations, 2: 10-23.

March, J. G., \& Simon, H. A. 1958. Organizations. New York, NY: Wiley.

Markman, G. D., Gianiodis, P. T., \& Buchholtz, A. K. 2009. Factor-market rivalry. Academy of Management Review, 34: 423-441.

Markman, G. D., \& Waldron, T. L. 2014. Small entrants and large incumbents: A framework of micro entry. Academy of Management Perspectives, 28: 179-197.

Markman, G. D., Waldron, T. L., \& Panagopoulos, A. 2016. Organizational hostility: Why and how nonmarket players compete with firms. Academy of Management Perspectives, 30: 74-92.

McGrath, R. G. 2013. The end of competitive advantage: How to keep your strategy moving as fast as your business. Boston, MA: Harvard Business Publishing.

McGrath, R. G., Chen, M.-J., \& MacMillan, I. C. 1998. Multimarket maneuvering in uncertain spheres of influence: Resource diversion strategies. Academy of Management Review, 23: 724-740.

McKelvey, B. 1997. Perspective-Quasi-natural organization science. Organization Science, 8: 351-380.

McMullen, J. S., Shepherd, D. A., \& Patzelt, H. 2009. Managerial (in) attention to competitive threats. Journal of Management Studies, 46: 157-181.

Miller, D., \& Chen, M.-J. 1994. Sources and consequences of competitive inertia: A study of the U.S. airline industry. Administrative Science Quarterly, 39: $1-23$.

Newman, M. E. J., \& Girvan, M. 2004. Finding and evaluating community structure in networks. Physical Review. E, 69: 026113

Ng, D. W. 2007. A modern resource based approach to unrelated diversification. Journal of Management Studies, 44: 1481-1502.

Ocasio, W. 1997. Towards an attention-based view of the firm. Strategic Management Journal, 18(Summer Special Issue): 187-206.

Ocasio, W., Laamanen, T., \& Vaara, E. 2018. Communication and attention dynamics: An attention-based view of strategic change. Strategic Management Journal, 39: $155-167$.

Pacheco, D. F., \& Dean, T. J. 2015. Firm responses to social movement pressures: A competitive dynamics perspective. Strategic Management Journal, 36: 1093-1104.

Penrose, E. 1959. The theory of the growth of the firm. New York, NY: John Wiley\& Sons. 
Peteraf, M. A., \& Bergen, M. E. 2003. Scanning dynamic competitive landscapes: A market-based and resourcebased framework. Strategic Management Journal, 24: 1027-1041.

Pons, P., \& Latapy, M. 2005. Computing communities in large networks using random walks. International Symposium on Computer Information Sciences ISCIS 2005, 3733: 284-293.

Porac, J. F., Thomas, H., Wilson, F., Paton, D., \& Kanfer, A. 1995. Rivalry and the industry model of Scottish knitwear producers. Administrative Science Quarterly, 40: 203-227.

Priem, R. L., Li, S., \& Carr, J. C. 2012. Insights and new directions from demand-side approaches to technology innovation, entrepreneurship, and strategic management research. Journal of Management, 38: 346-374.

Raghavan, U. N., Albert, R., \& Kumara, S. 2007. Near linear time algorithm to detect community structures in large-scale networks. Physical Review. E, 76: 036106.

Rogan, M., \& Sorenson, O. 2014. Picking a (poor) partner: A relational perspective on acquisitions. Administrative Science Quarterly, 59: 301-329.

Rosvall, M., \& Bergstrom, C. T. 2008. Maps of information flow reveal community structure in complex networks. Proceedings of the National Academy of Sciences, 105: 1118-1123.

Rumelt, R. P. 1974. Strategy, structure, and economic performance. Cambridge, MA: Harvard University Press.

Santalo, J., \& Becerra, M. 2008. Competition from specialized firms and the diversification-performance linkage. Journal of Finance, 63: 851-883.

Schmid, C. S., \& Desmarais, B. A. 2017. Exponential random graph models with big networks: Maximum pseudolikelihood estimation and the parametric bootstrap. Paper presented at the IEEE International Conference on Big Data, Boston, MA.

Schmidt, J., Makadok, R., \& Keil, T. 2016. Customerspecific synergies and market convergence. Strategic Management Journal, 37: 870-895.

Shen, Q., \& Villas-Boas, J. M. 2010. Strategic entry before demand takes off. Management Science, 56: 1259-1271.

Sirmon, D. G., Hitt, M. A., Arregle, J. L., \& Campbell, J. T. 2010. The dynamic interplay of capability strengths and weaknesses: Investigating the bases of temporary competitive advantage. Strategic Management Journal, 31: 1386-1409.

Skilton, P. F., \& Bernardes, E. 2015. Competition networks structure and product market entry. Strategic Management Journal, 36: 1688-1696.

Smith, K. G., Ferrier, W. J., \& Ndofor, H. 2001. Competitive dynamics research: Critique and future directions. In
M. Hitt, R. E. Freeman, \& J. Harrison (Eds.), Handbook of strategic management: 315-361. London, U.K.: Blackwell Publishers.

Smith, K. G., Grimm, C. M., Wally, S., \& Young, G. 1997. Strategic groups and rivalrous firm behavior: Towards a reconciliation. Strategic Management Journal, 18: 149-157.

Snijders, T. A. 1996. Stochastic actor-oriented models for network change. Journal of Mathematical Sociology, 21: 149-172.

Snijders, T. A. B., Van de Bunt, G. G., \& Steglich, C. E. G. 2010. Introduction to stochastic actor-based models for network dynamics. Social Networks, 32: 44-60.

Sonenshein, S., Nault, K., \& Obodaru, O. 2017. Competition of a different flavor: How a strategic group identity shapes competition and cooperation. Administrative Science Quarterly, 62: 626-656.

Sytch, M., \& Tatarynowicz, A. 2014. Friends and foes: The dynamics of dual social structures. Academy of Management Journal, 57: 585-613.

Terwiesch, C., \& Ulrich, K. T. 2009. Innovation tournaments: Creating and selecting exceptional opportunities. Boston, MA: Harvard Business Publishing.

Thompson, V. 2015. Worldwide enterprise social networks online communities 2015-2019 and 2014 vendor shares (IDC5639237 Industry Report). Retrieved from https://www.marketresearch.com/ IDC-v2477/Worldwide-Enterprise-Social-NetworksOnline-9182617.

Tsai, W., Su, K.-H., \& Chen, M.-J. 2011. Seeing through the eyes of a rival: Competitor acumen based on rivalcentric perceptions. Academy of Management Journal, 54: 761-778.

Upson, J. W., Ketchen, D. J., Connelly, B. L., \& Ranft, A. L. 2012. Competitor analysis and foothold moves. Academy of Management Journal, 55: 93-110.

Uzunca, B. 2018. A competence-based view of industry evolution: The impact of submarket convergence on incumbent-entrant dynamics. Academy of Management Journal, 61: 738-768.

Vuori, T. O., \& Huy, Q. N. 2016. Distributed attention and shared emotions in the innovation process: How Nokia lost the smartphone battle. Administrative Science Quarterly, 61: 9-51.

Wasserman, S., \& Pattison, P. 1996. Logit models and logistic regressions for social networks: I. An introduction to Markov graphs and p. Psychometrika, 61: 401-425.

Wiersema, M. F., \& Bowen, H. P. 2008. Corporate diversification: The impact of foreign competition, industry globalization, and product diversification. Strategic Management Journal, 29: 115-132.

Withers, M. C., Ireland, R. D., Miller, D., Harrison, J. S., \& Boss, D. S. 2018. Competitive landscape shifts: The influence of 
strategic entrepreneurship on shifts in market commonality. Academy of Management Review, 43: 349-370.

Ye, G., Priem, R. L., \& Alshwer, A. A. 2012. Achieving demand-side synergy from strategic diversification: How combining mundane assets can leverage consumer utilities. Organization Science, 23: 207-224.

Yu, T., \& Cannella, A. A. 2007. Rivalry between multinational enterprises: An event history approach. Academy of Management Journal, 50: 665-686.

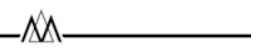

Stephen T. Downing (sdowning.bm02g@nctu.edu.tw) is a $\mathrm{PhD}$ candidate in strategic management at National Chiao Tung University, Taiwan. His research explores how firms understand and engage with their competitive environment, incorporating market and nonmarket competitive dynamics and interorganizational networks.

Jin-Su Kang (jinsu.kang@g2.nctu.edu.tw) is an associate professor of strategy at National Chiao Tung University, Taiwan. She received her PhD from Korea Advanced Institute of Science and Technology (KAIST). She studies competitive dynamics, innovation, and strategic corporate social responsibility.

Gideon D. Markman (gid.markman@gmail.com) is a professor of strategy, entrepreneurship, and sustainable enterprise at Colorado State University and Gent University. He earned his $\mathrm{PhD}$ from the University of ColoradoBoulder. He studies competitive dynamics, market entry, and the sharing economy, as well as social, environmental, sustainable, and impact entrepreneurship.

$M$ 


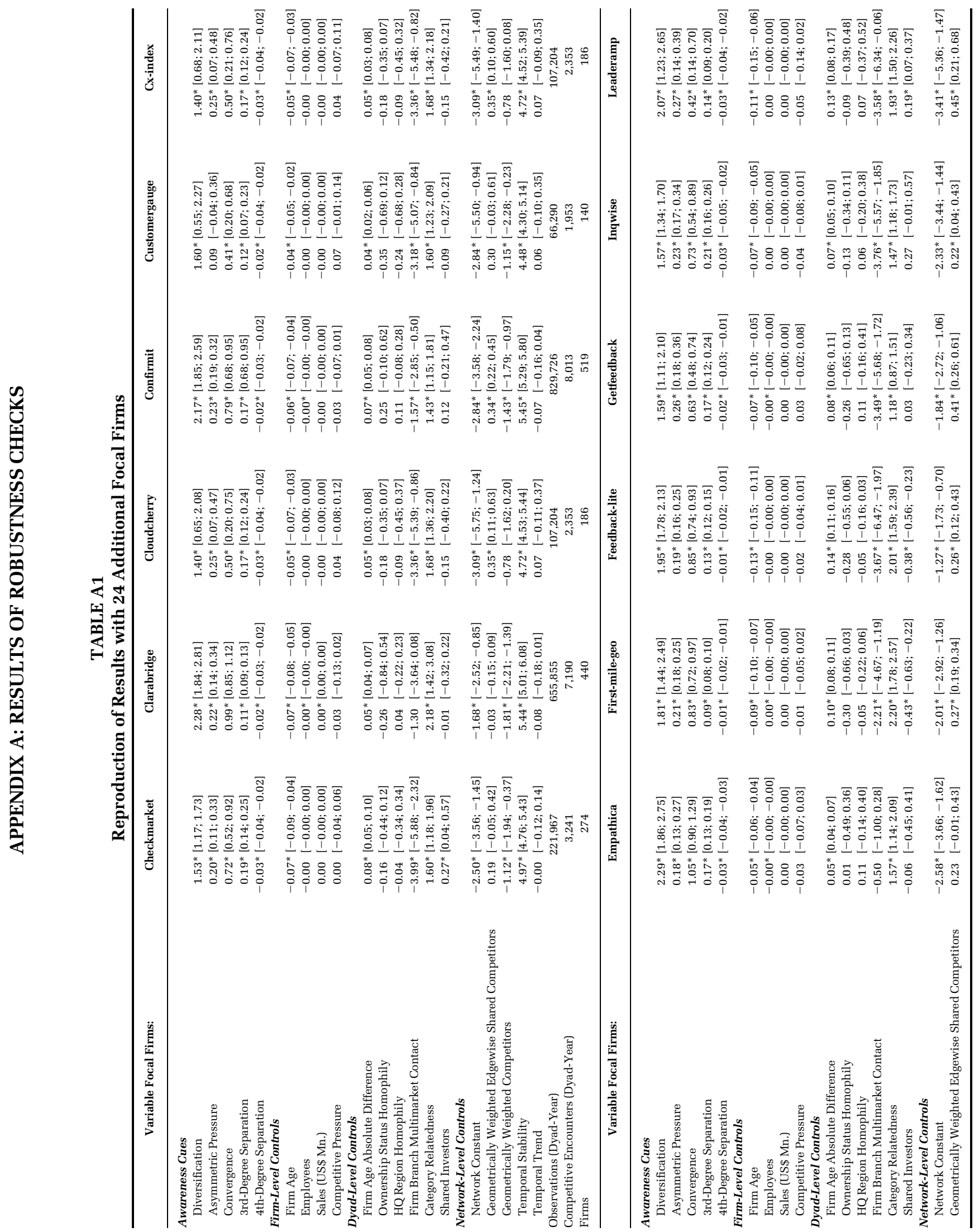




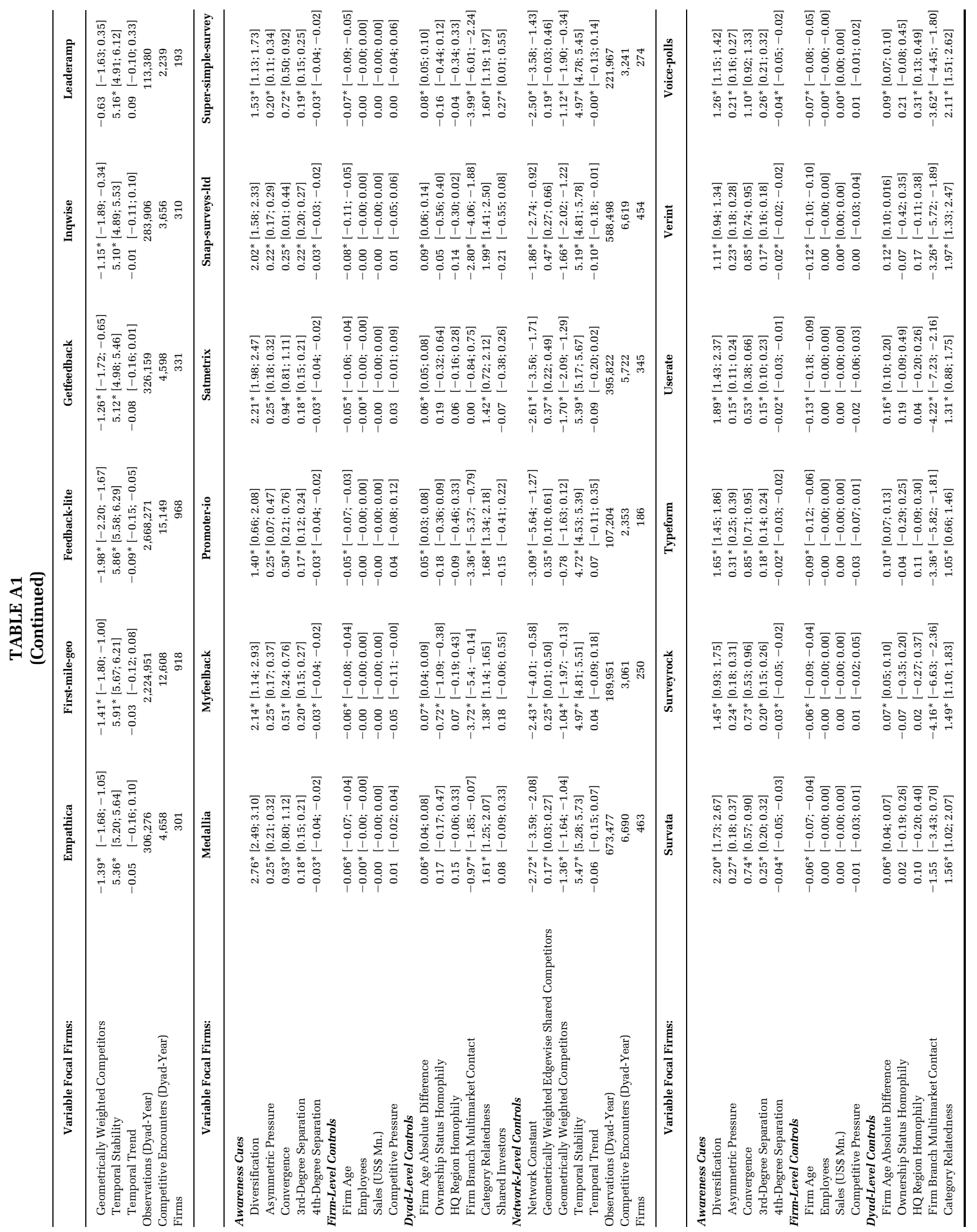



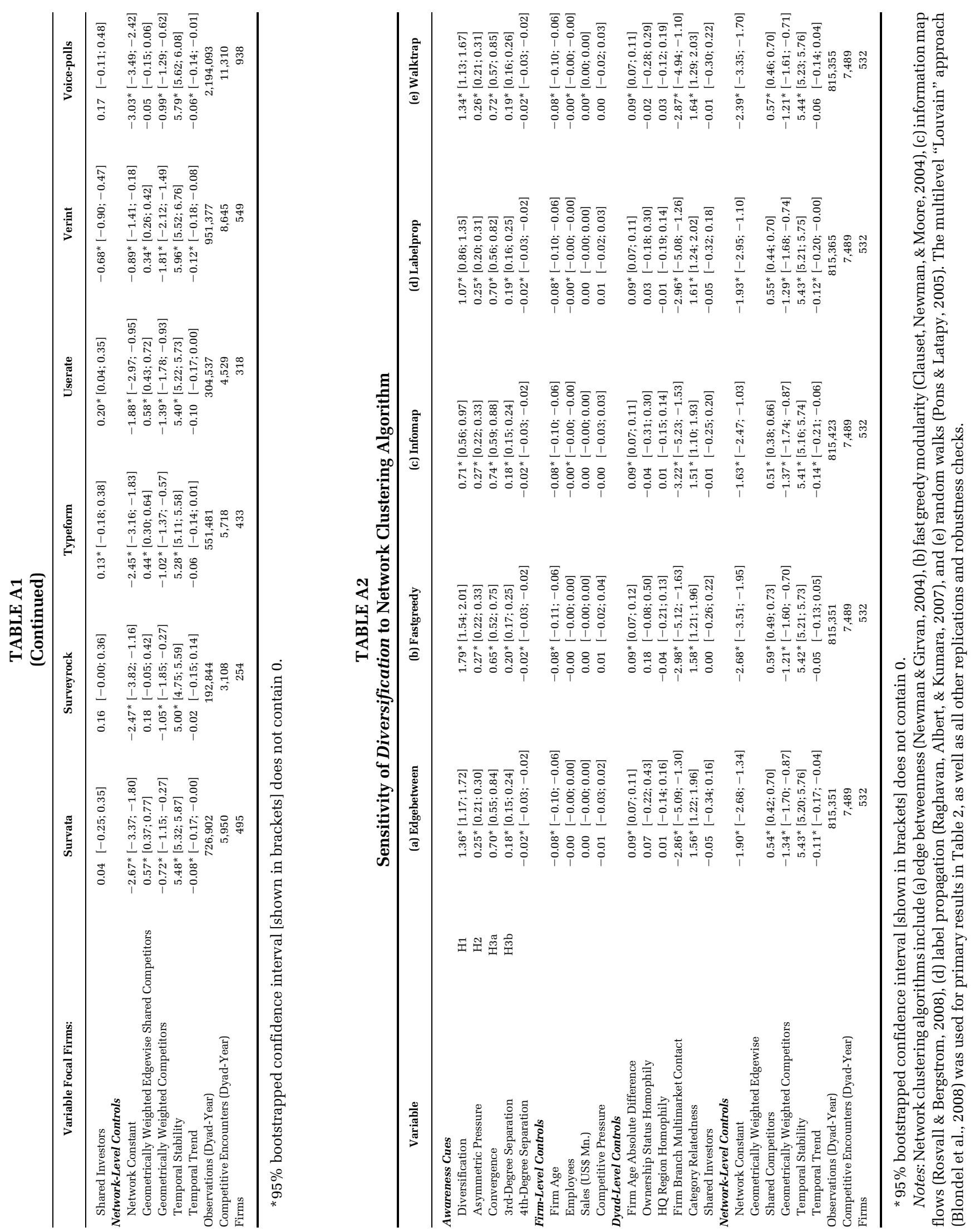


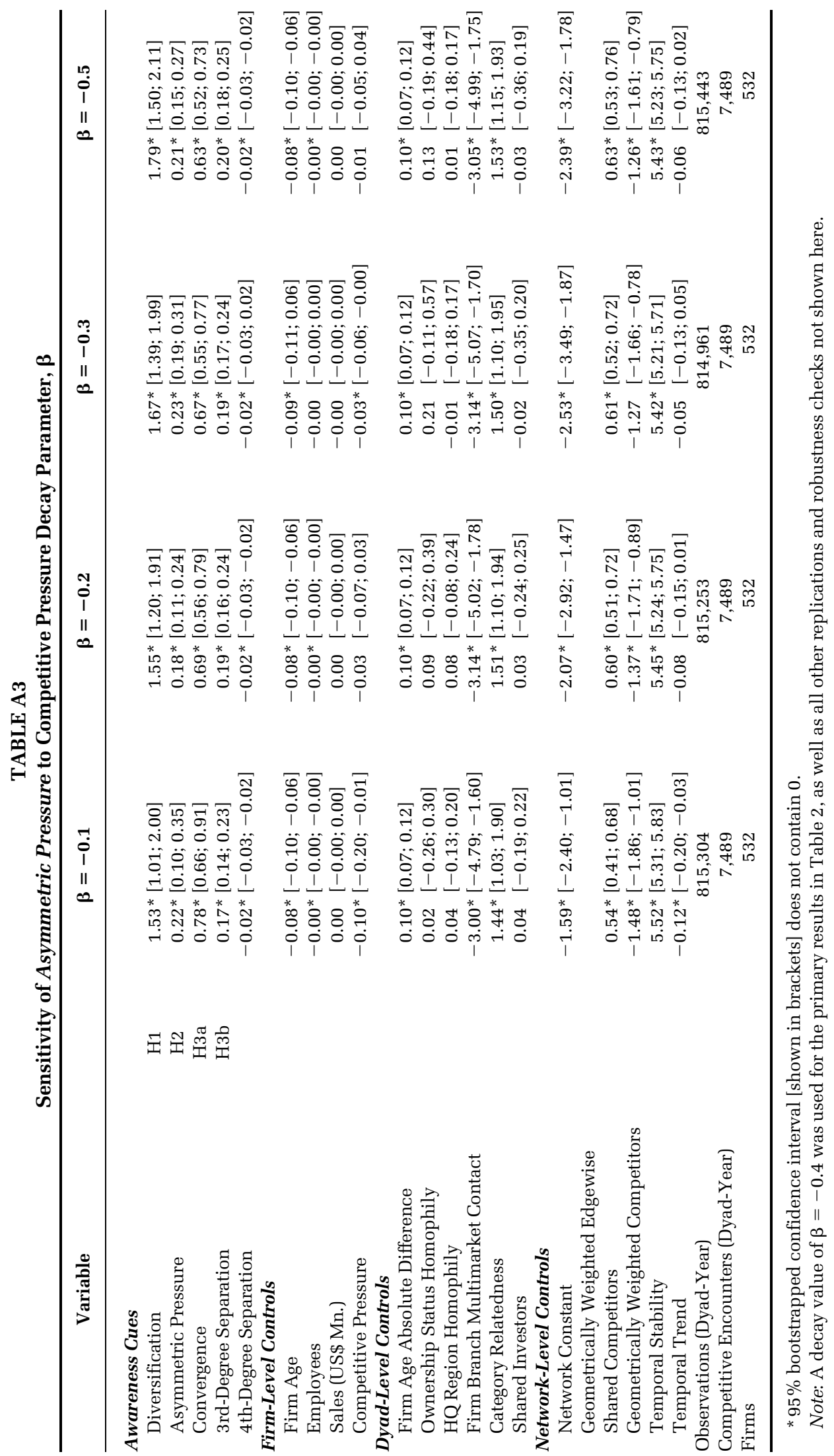


TABLE A4

Sensitivity of Degree of Separation to Cohort Selection Threshold and Higher $k$-Cycles

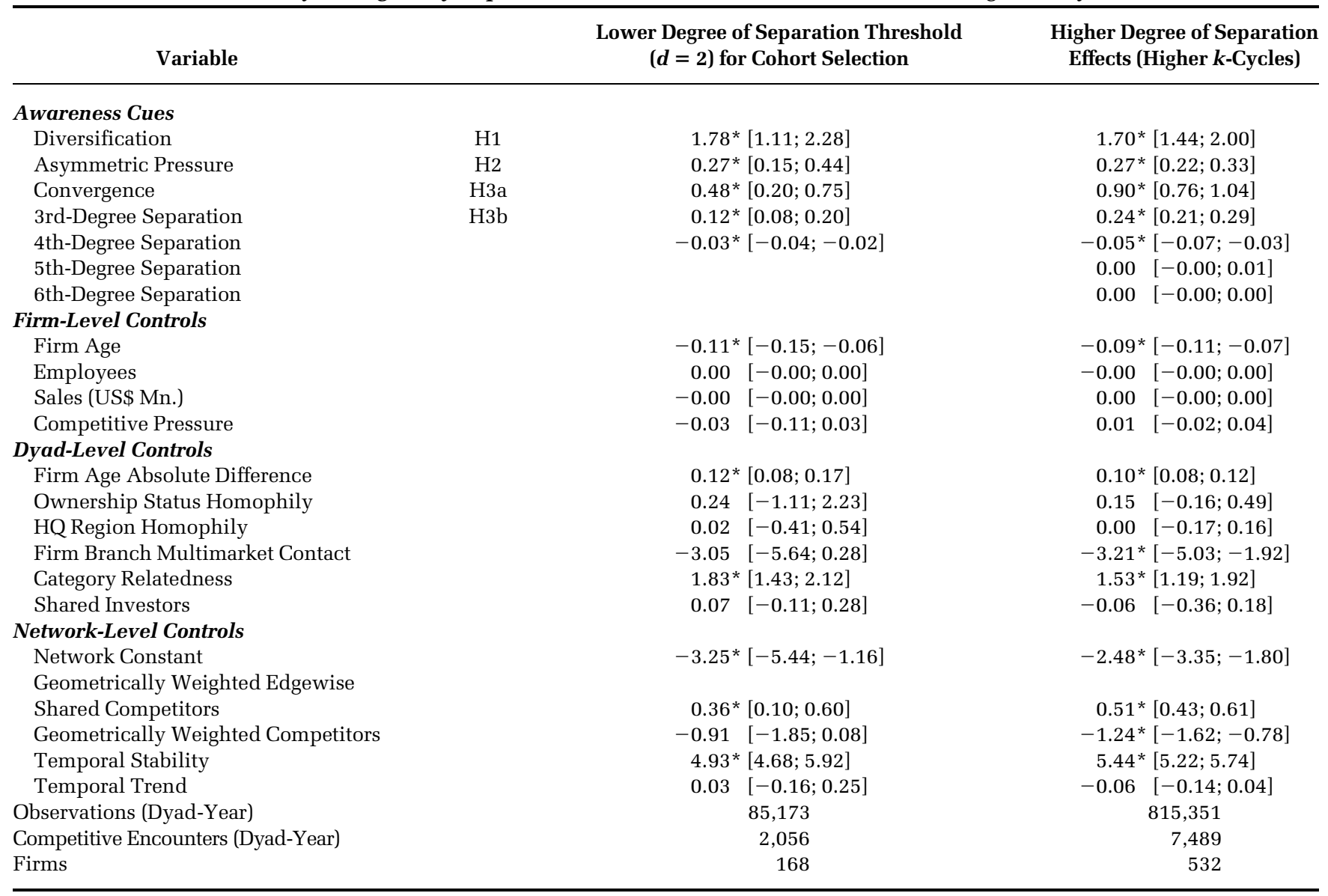

* $95 \%$ bootstrapped confidence interval [shown in brackets] does not contain 0 . 
Copyright of Academy of Management Journal is the property of Academy of Management and its content may not be copied or emailed to multiple sites or posted to a listserv without the copyright holder's express written permission. However, users may print, download, or email articles for individual use. 